Article

\title{
Sensor Capability and Atmospheric Correction in Ocean Colour Remote Sensing
}

\author{
Simon Emberton ${ }^{1, *}$, Lars Chittka ${ }^{1}$, Andrea Cavallaro ${ }^{1}$ and Menghua Wang ${ }^{2}$ \\ Received: 5 October 2015/Accepted: 24 November 2015/Published: 22 December 2015 \\ Academic Editors: Xiaofeng Li and Prasad S. Thenkabail \\ 1 Centre for Intelligent Sensing, Queen Mary University of London, London, E1 4NS, UK; \\ 1.chittka@qmul.ac.uk (L.C.); a.cavallaro@qmul.ac.uk (A.C.) \\ 2 National Oceanic and Atmospheric Administrations, Center for Satellite Applications and Research, \\ College Park, MD 20740, USA; menghua.wang@noaa.gov \\ * Correspondence: s.emberton@qmul.ac.uk; Tel.: +44-(0)20-7882-7549
}

\begin{abstract}
Accurate correction of the corrupting effects of the atmosphere and the water's surface are essential in order to obtain the optical, biological and biogeochemical properties of the water from satellite-based multi- and hyper-spectral sensors. The major challenges now for atmospheric correction are the conditions of turbid coastal and inland waters and areas in which there are strongly-absorbing aerosols. Here, we outline how these issues can be addressed, with a focus on the potential of new sensor technologies and the opportunities for the development of novel algorithms and aerosol models. We review hardware developments, which will provide qualitative and quantitative increases in spectral, spatial, radiometric and temporal data of the Earth, as well as measurements from other sources, such as the Aerosol Robotic Network for Ocean Color (AERONET-OC) stations, bio-optical sensors on Argo (Bio-Argo) floats and polarimeters. We provide an overview of the state of the art in atmospheric correction algorithms, highlight recent advances and discuss the possible potential for hyperspectral data to address the current challenges.
\end{abstract}

Keywords: atmospheric correction; hyperspectral; multispectral; ocean colour; remote sensing

\section{Introduction}

Sensors mounted on satellites and aeroplanes have been monitoring the spectral properties of ocean water for over three decades [1-3]. Applications include climate research and characterisation of the atmosphere [4], ecological conservation [5], understanding the structure and function of marine ecosystems [6,7] and coastal and inland water studies [8-10]. There is a large variety in the spectral properties of different bodies of water with dramatic changes occurring with location and time of year. The colour of water can provide insights into the content of the water, such as levels of pollution and chlorophyll [11]. Even though, strictly speaking, colour is a perceptual term and not a physical property of objects [12], for simplicity, we use the term "colour" to describe spectral properties. Sensors with more than three bands (multispectral sensors) enable surface spectra to be captured in more detail than is possible with RGB cameras or the human eye. In ocean colour remote sensing, a distinction is made between multispectral and hyperspectral measurements. Multispectral sensors generally possess fewer spectral bands than hyperspectral sensors [13]. However, the principal difference is not the number of bands, but rather where the bands are located along the wavelength scale. Those of multispectral sensors are positioned with gaps between them, while the bands in hyperspectral sensors are contiguously positioned along the spectrum [13]. In the past, ocean colour remote sensors predominantly captured multispectral data, e.g., the Coastal Zone Color Scanner (CZCS) [2,14], the Sea-viewing Wide Field-of-View Sensor (SeaWiFS) [15], the Moderate-Resolution Imaging Spectroradiometer (MODIS) [3], the Medium-Resolution Imaging Spectrometer (MERIS) [16] 
and the Visible Infrared Imaging Radiometer Suite (VIIRS) [17]. We are starting to see a move towards hyperspectral sensors [18-21], which brings with it both advantages and challenges. The advantages of hyperspectral data are that they can facilitate the use of spectroscopic techniques that analyse the spectral signal, such as derivative analysis [22], and if atmospheric effects are accurately corrected for, this technique can permit an improved understanding of bio-optical water properties, especially in complex turbid waters [23]. Past reviews suggest a hyperspectral resolution enables more accurate retrievals of biophysical properties due to its ability to sense in the narrow bands that characterise individual biophysical properties [24,25]. Another advantage with hyperspectral data is that they remove the need to choose the location of bands beforehand and permit retrievals over a range of regions and conditions [26].

One of the key challenges in capturing accurate satellite-based measurements of bodies of water is to correct for unwanted radiance contributions to the signal. In remote sensing, the contributions to the top-of-atmosphere (TOA) signal that reach a sensor contain atmospheric effects, water surface effects and water-leaving radiance. The water-leaving radiance generally only accounts for around $10 \%$ of the TOA signal [27], with the rest of the signal being corrupted by atmospheric and surface effects. The atmospheric correction process aims to take into account all of the contributions to the signal, so that the apparent optical properties (AOPs), such as normalised water-leaving radiance (or remote sensing reflectance), can be accurately retrieved. AOPs depend on the medium and on the geometric (directional) structure of the ambient light field [27-29]. Large errors can be introduced if the atmospheric correction step is done incorrectly, and this can lead to inaccuracies in the retrieval of AOPs [27,30]. These estimates are then used to derive the biological and biogeochemical properties of the water, such as concentrations of phytoplankton and chlorophyll- $a$ [31], total suspended matter [32-34], coloured dissolved organic matter (CDOM) and detritus, or the inherent optical properties (IOPs) of the water, such as the absorption and scattering coefficients $[35,36]$. Phytoplankton is the primary producer in the ocean and plays an important role in the carbon cycle of the planet. Monitoring its levels and distribution provides insight into life in the ocean. A notable example is the case of algal blooms (Figure 1), some of which can be toxic, and which are the result of a population of phytoplankton rapidly increasing in size.

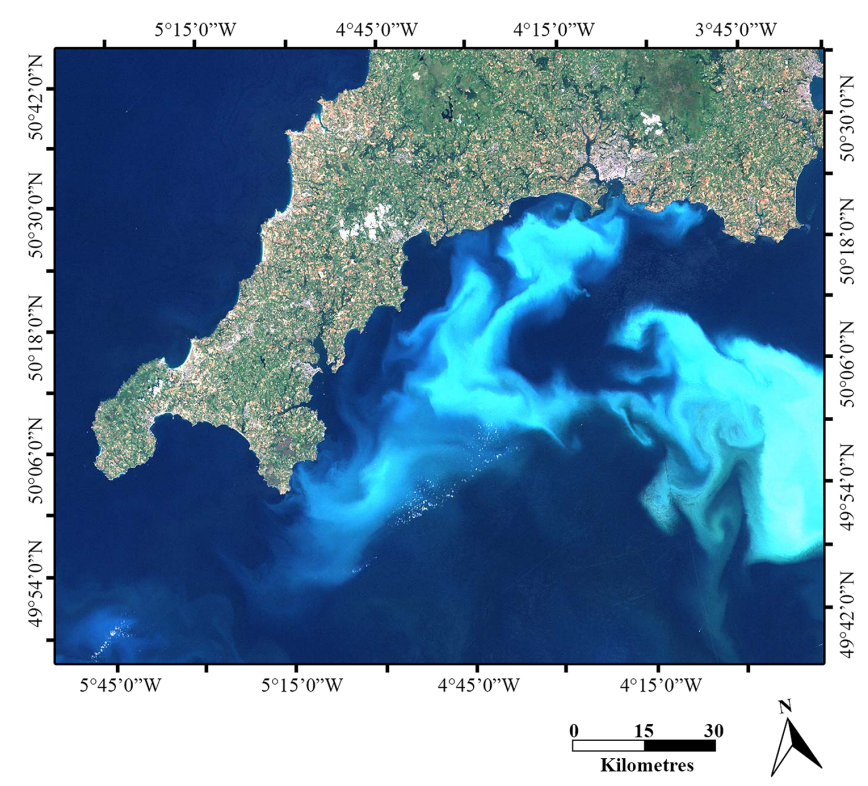

Figure 1. Satellite image of an algal bloom off the southwest coast of England. This Landsat 7 false colour image was taken on 24 July 1999 and shows the spread of phytoplankton E. huxleyi, a species of coccolithophore. Image provided by the NERC EO Data Acquisition and Analysis Service Plymouth, with permission from S. Groom [37]. Approximate scale, north arrow and coordinates. 
The 10th report from the International Ocean Colour Coordinating Group (IOCCG) compared four atmospheric correction techniques and found that over the open ocean, with conditions of nonor weakly-absorbing aerosols could be considered a solved problem [30]. The areas that still require further research are turbid waters and conditions of strongly-absorbing aerosols [30]. These cases mostly occur in coastal and inland waters because of terrestrial influences, a general abundance of more phytoplankton and a temporally- and spatially-variable environment [38]. These waters are also the sites of the majority of human activity, and as such, accurate retrievals from these locations are of a high importance. Over these complex waters, current sensors and algorithms frequently produce errors with estimates of the normalised water-leaving radiance often being given a low bias and even sometimes a negative result in the short wavelength region [39]. Studies have compared the accuracy of atmospheric correction algorithms in turbid waters [40-42]. Some significant progress has been made for retrievals over turbid coastal and inland waters with the shortwave infrared (SWIR) based atmospheric correction algorithms in particular [29,40,43,44]. Recent reviews [45,46] have outlined advances in sensor technology, made suggestions for future missions and highlighted the challenges facing ocean colour remote sensing.

In this paper, we provide an overview of ocean colour sensors and atmospheric correction algorithms. We highlight how sensors with increased spectral, spatial, radiometric and temporal resolutions and combining data from other sources, such as the Aerosol Robotic Network for Ocean Color (AERONET-OC) [47] and polarimeters, have the potential to overcome the challenges for atmospheric correction over complex coastal and inland waters. We also show how this increase in data can facilitate the development of novel aerosol models and algorithmic approaches. We review sensors, providing an outlook on developing and future technology, with particular focus on addressing upcoming hyperspectral missions. The contributions to the TOA signal are outlined with a focus on atmospheric and water surface effects. We also provide an overview of the state of the art in atmospheric correction algorithms and discuss the opportunities and challenges for hyperspectral measurements.

\section{Ground-Based Sensors}

Ground-based sensors can be used to validate and vicariously calibrate data from satellite-mounted sensors [48-50] and to assist in the atmospheric correction process of ocean colour sensors [51]. In satellite ocean colour remote sensing, vicarious calibration [48] is necessary and has been done using natural targets (clear and relatively uniform waters), such as the Marine Optical Buoy (MOBY) in Hawaii [52], where the spectral reflectance of the targets has been verified via in situ measurements [53]. In fact, the vicarious calibration for a satellite ocean colour sensor is the calibration for the entire system, including sensors and algorithms (particularly for atmospheric correction) [48].

\subsection{Land-Based Sensors}

AERONET was set up as a way to monitor the optical properties of atmospheric aerosols which work towards supporting satellite captured data on both a global and regional scale [47,54]. Spectral radiometers capture measurements of the sun to determine aerosol optical depth (sometimes termed aerosol optical thickness) and water vapour levels. Measurements of the sky radiance are also compared to the direct sun measurements to determine the size distribution and phase function of the aerosols [54]. The data are then distributed in near real time and can be used in conjunction with remotely-sensed data [54]. AERONET-OC [55] has been added to some of the coastal AERONET stations so that, as well as providing aerosol optical properties, ocean colour instruments can continuously monitor water-leaving radiances throughout the visible and near infrared (NIR) wavelength ranges [47]. 


\subsection{Sea-Based Sensors}

As AERONET stations are restricted to land, the ship-based Maritime Aerosol Network (MAN) [56] has extended AERONET measurements into open ocean locations [57]. There are also a number of moored buoys, such as the Boussole buoy [58] and MOBY [52,59], which are equipped with measuring instruments that facilitate the validation and calibration of satellite-based ocean colour sensors. The Boussole buoy has been moored in the Mediterranean Sea since 2003 and has been used for the calibration and validation of MERIS, SeaWiFS, MODIS and Polarization and Directionality of the Earth's Reflectances (POLDER) [58]. This buoy measures upward and downward radiance, beam attenuation, backscattering, and phytoplankton and chlorophyll fluorescence [58]. These measurements are complemented by a monthly research cruise program and a nearby AERONET station [58]. MOBY is moored off the island of Lanai in Hawaii [60], and the site is usually in stable and oligotrophic (clear-ocean) waters. The MOBY program has been providing consistently high-quality clear-ocean optics data since 1997, supporting various satellite ocean colour missions, such as SeaWiFS [61], MODIS [50], the Ocean Color and Temperature Scanner (OCTS), POLDER [53,59,62] and VIIRS [17]. MOBY in situ data are available from the NOAA CoastWatch website [63]. In a recent study, Wang et al. [64] showed that accurate long-term and consistent MOBY data can be used not only for the required system vicarious calibration [65] for satellite ocean colour data processing, but also to characterise and monitor both the short-term and long-term sensor on-orbit performance.

An extensive network of Argo floats throughout the world's oceans measure temperature and salinity [66]. In 2008, the IOCCG set up a working group to focus on extending this network of profiling floats for the benefit of the ocean colour community. These new Bio-Argo floats collect radiometric and bio-optical data and increase the density of measurements that can be used as a ground truth to compare to the output of inversion algorithms or to compliment remotely-sensed data by providing insight into the previously unknown vertical dimension of the world's oceans [67]. Studies into bio-optical properties have made use of Bio-Argo floats to investigate CDOM dynamics in the Mediterranean [68], phytoplankton dynamics in the oligotrophic layer of the subtropical Pacific and the Mediterranean [69] and the interrelationships between chlorophyll- $a$ concentration, the backscattering coefficient and the beam attenuation coefficient in the North Atlantic [70]. Another study combined satellite and float data to explore the interplay between nitrates and chlorophyll concentrations in the Mediterranean [71]. Progress has also been made in the realisation of low-cost small-scale solutions to water monitoring, which could be distributed on a large scale and used to complement remotely-sensed data [72]. In particular, a recent study demonstrated a device that makes use of two filters and a CMOS sensor array to measure the fluorescent properties of chlorophyll- $a$ and CDOM molecules [72].

The SeaWiFS Bio-optical Archive and Storage System (SeaBASS) is a repository database that contains data collected through NASA and other programs that are used for ocean colour products' validation and the evaluation of algorithms within the ocean colour community [73]. This includes in situ optical, bio-optical and atmospheric measurements from the international community and incorporates data collected from MOBY and AERONET-OC [73].

\section{Remote Sensors}

\subsection{Sensor Resolutions}

The first space-based multispectral sensor for ocean colour remote sensing was Coastal Zone Color Scanner (CZCS), which was launched by NASA in 1978 [2,14]. CZCS featured six separate channels; the first four, at $433-453 \mathrm{~nm}, 510-530 \mathrm{~nm}, 540-560 \mathrm{~nm}$ and $660-680 \mathrm{~nm}$, were used to monitor concentrations of chlorophyll- $a$ and for atmospheric correction [2,14]. The fifth channel at 700-800 nm was used to discriminate clouds and land from the open ocean, as well as to map surface vegetation. The sixth channel, a thermal band at 10,500-12,500 nm, was used to monitor 
ocean temperatures [14]. The spatial resolution of CZCS was $825 \mathrm{~m}$. More recent ocean colour sensors capture images with higher spatial and spectral resolutions. For example, the recently retired (September 2014) Hyperspectral Imager for the Coastal Ocean (HICO) [18] on board the International Space Station had 128 bands ranging from 380-960 nm and, as such, captured a much more detailed spectral signal at each pixel in a scene than was possible with CZCS. The spatial resolution (90 m) was also much more precise for each pixel. Multispectral and hyperspectral ocean colour sensors are compared in Table 1 [14,18-21,74-93].

While the majority of remote sensing platforms are satellites, hyperspectral imagers have been mounted onto aeroplanes, such as the Airborne Visible/Infrared Imaging Spectrometer (AVIRIS) [74], AVIRIS Next Generation (AVIRIS-NG) [83] and the Portable Remote Imaging Spectrometer (PRISM) [86]. We are also starting to see lightweight systems being developed specifically for use with unmanned aerial vehicles (UAVs) [94]. A satellite-based sensor is able to cover a larger area than an aeroplane or UAV, although at a lower spatial resolution. Nowadays, space-based sensors possess more and more detailed spatial resolutions. A spatial resolution of $100 \mathrm{~m}$ has been recommended in order to characterise coastal waters [95,96]. However, a more detailed resolution is required for areas that contain a high diversity of phytoplankton in certain coastal and inland waters $[26,46]$. The Landsat missions were not intended to be used for ocean colour remote sensing; however, due to their high spatial resolution, they have been useful for the characterisation of complex coastal waters $[97,98]$. The Operational Land Imager (OLI) onboard Landsat 8 has a spatial resolution of $30 \mathrm{~m}$, which facilitates the identification of small-scale turbidity features and is able to show that suspended sediments in coastal waters are spatially highly variable [99].

The first space-based hyperspectral sensors (Compact High Resolution Imaging Spectrometer (CHRIS) [79] and Hyperion [78]) brought the advantages of airborne hyperspectral imagers (high spectral and spatial resolution) to larger areas and for much longer time scales. Unfortunately, both of these sensors have been plagued with issues, such as unreliable spectral and radiometric calibration [100] and their low signal-to-noise ratio (SNR), especially over bodies of water, and this often leads to poor retrievals [101,102], e.g., the SNR of Hyperion ranges between 50:1 and 150:1 [103]. As HICO was specifically developed for ocean colour sensing, its 128 bands, which cover a spectral range from 380-960 nm, capture with a reasonable SNR (>200:1 for water-penetrating wavelengths and assuming 5\% albedo) [18]. The high spectral resolution of HICO was applied to a variety of applications, such as the removal of thin cirrus clouds [104], estimation of the levels of chlorophyll- $a$ [105], detection of red tide [106], monitoring the quality of water [107] and the mapping of seagrass [108]. No standard atmospheric correction method was developed for HICO, and one method that has been used is Tafkaa [109]. Tafkaa makes use of the black pixel approach, which assumes that the water-leaving radiance is equal to zero in the NIR or SWIR, and the measurements taken from a band in one of these regions only contain aerosol effects. Turbid waters do not have zero water-leaving radiance in the NIR bands $[43,110,111]$, and one limitation with HICO was its lack of SWIR bands. For HICO to achieve accurate retrievals over turbid waters, measurements of the aerosol optical depth [112] and aerosol type [113] needed to be either estimated or measured from other sources, such as AERONET. Other limitations include the fact that HICO suffered from spectral shifts (of up to $1 \mathrm{~nm}$ ) and a low radiometric sensitivity (especially below $450 \mathrm{~nm}$ ) [102]; it was not designed for regular global coverage [114], and its location on the International Space Station only permitted data capture within the latitude range $\approx+54^{\circ} /-53^{\circ}$ (which covered around $80 \%$ of the Earth's surface) [115]. 
Table 1. Multispectral and hyperspectral ocean colour remote sensors. The table shows how there is a trend towards hyperspectral sensors (grey) and an increase in spectral and spatial resolution. Geostationary orbits will also provide an increase in temporal resolution. Key: - , Not known at the time of submission; Spatial Res., Spatial Resolution; CZCS, Coastal Zone Color Scanner; AVIRIS, Airborne Visible/Infrared Imaging Spectrometer; OCTS, Ocean Color and Temperature Scanner; SeaWiFS, Sea-viewing Wide Field-of-View Sensor; ETM+, Enhanced Thematic Mapper Plus; CHRIS, Compact High Resolution Imaging Spectrometer; MERIS, Medium-Resolution Imaging Spectrometer; MODIS, Moderate-Resolution Imaging Spectroradiometer; POLDER, Polarization and Directionality of the Earth's Reflectances; NG, Next Generation; HICO, Hyperspectral Imager for the Coastal Ocean; GOCI, Geostationary Ocean Color Imager; VIIRS, Visible Infrared Imaging Radiometer Suite; PRISM, Portable Remote Imaging Spectrometer; OLI, Operational Land Imager; TIRS, Thermal Infrared Sensor; SGLI, Second Generation Global Imager; OLCI, Ocean and Land Colour Instrument; HISUI, Hyperspectral Imager Suite; MSS, Multi Spectral Sensor; HSS, Hyper Spectral Sensor; PRISMA, Precursore Iperspettrale della Missione Operativa; EnMAP, Environmental Mapping and Analysis Program; OCI, Ocean Color Instrument; OES, Ocean Ecology Sensor; HyspIRI, Hyperspectral Infrared Imager; ADEOS, Advanced Earth Observing Satellite; EO, Earth Observing; EOS, Earth Observing System; PARASOL, Polarization and Anisotropy of Reflectances for Atmospheric science coupled with Observations from a Lidar; COMS, Communication, Ocean and Meteorological Satellite; S-NPP, Suomi National Polar-orbiting Partnership; JPSS, Joint Polar Satellite System; GCOM, Global Change Observation Mission; ALOS, Advanced Land Observation Satellite; PACE, Pre-Aerosol, Clouds and Ocean Ecosystem; ACE, Aerosol Cloud Ecosystem; GEO-CAPE, Geostationary Coastal and Air Pollution Events.

\begin{tabular}{|c|c|c|c|c|c|c|c|c|c|c|}
\hline Ref. & Sensor & No. of Bands & Spectral Range (nm) & Spatial Res. (m) & Coverage $(\mathrm{km})$ & Orbit & Revisit (Days) & Location & Origin & Launch \\
\hline [14] & CZCS & 5 and 1 & $433-800$ and $10,000-12,500$ & 825 & 1556 & Sun-sync & 6 & Nimbus 7 & USA & 1978 \\
\hline [74] & AVIRIS & 224 & $410-2500$ & N/A & $\mathrm{N} / \mathrm{A}$ & N/A & N/A & Airborne & USA & 1987 \\
\hline [75] & OCTS & 8 and 4 & $402-885$ and $3550-12,700$ & 700 & 1400 & Sun-sync & 41 & ADEOS & Japan & 1996 \\
\hline [76] & SeaWiFS & 8 & $402-885$ & 1100 & 2801 & Sun-sync & 1 & OrbView-2 & USA & 1997 \\
\hline [77] & ETM+ & 8 & $450-2350$ & $30 / 60$ & 185 & Sun-sync & 16 & Landsat 7 & USA & 1999 \\
\hline [78] & Hyperion & 220 & $400-2500$ & 30 & $7.5 \times 100$ & Sun-sync & 16 & EO-1 & USA & 2000 \\
\hline [79] & CHRIS & $19 / 63$ & $415-1050$ & $18 / 36$ & 14 & Sun-sync & 7 & Proba-1 & $\mathrm{EU}$ & 2001 \\
\hline [80] & MERIS & 15 & $390-1040$ & $300 / 1200$ & 1150 & Polar & 3 & Envisat-1 & EU & 2002 \\
\hline [81] & MODIS Aqua & 19 and 16 & $405-2155$ and $3660-14,385$ & $250 / 500 / 1000$ & 2330 & Sun-sync & $1-2$ & EOS-PM & USA & 2002 \\
\hline [82] & POLDER 3 & 15 & $443-1020$ & 6000 & 2400 & Sun-sync & - & PARASOL & France & 2004 \\
\hline [83] & AVIRIS-NG & 426 & $380-2510$ & N/A & N/A & N/A & N/A & Airborne & USA & 2009 \\
\hline [18] & HICO & 128 & $380-960$ & 90 & $\sim 42 \times 192$ & ISS orbit & $\sim 10$ & International Space Station & USA & 2009 \\
\hline [84] & GOCI & 8 & $412-865$ & 500 & 2500 & Geostationary & $1 / 24$ & COMS & S. Korea & 2010 \\
\hline [85] & VIIRS & 15 and 7 & $402-2280$ and $3550-12,490$ & $375 / 750$ & 3000 & Sun-sync & 1 & S-NPP and JPSS & USA & 2011 \\
\hline [86] & PRISM & 202 & $350-1050$ and 1240,1610 & N/A & N/A & N/A & N/A & Airborne & USA & 2012 \\
\hline [77] & OLI/TIRS & 9 and 2 & $435-2294$ and $10,600-12,510$ & $30 / 60$ & 185 & Sun-sync & 16 & Landsat 8 & USA & 2013 \\
\hline [87] & SGLI & 19 & $380-865$ & 250 & 1150 & Sun-sync & $1-3$ & GCOM-C1 & Japan & 2017 \\
\hline [88] & OLCI & 21 & $400-1020$ & $300 / 1200$ & 1270 & Sun-sync & $\sim 2$ & Sentinel-3 & Europe & 2015 \\
\hline [19] & HISUI (MSS) & 4 & $485-835$ & 5 & 90 & Sun-sync & 60 & ALOS-3 & Japan & 2015 \\
\hline [19] & HISUI (HSS) & 185 & $400-2500$ & 30 & 30 & Sun-sync & 60 & ALOS-3 & Japan & 2015 \\
\hline [20] & PRISMA & 237 & $400-2505$ & 30 & 30 & Sun-sync & 3.5 & PRISMA & Italy & 2015 \\
\hline [89] & EnMAP & 244 & $420-2450$ & 30 & 30 & Sun-sync & 4 & EnMAP & Germany & 2017 \\
\hline [91] & OCI & - & - & - & - & Polar & - & PACE & USA & 2018 \\
\hline [92] & GOCI-II & 13 & 360-900 & 250 & 2500 & Geostationary & $1 / 48$ & GeoKompsat2B & S. Korea & 2018 \\
\hline [90] & OES & - & - & - & - & Polar & - & ACE & USA & $>2020$ \\
\hline [93] & - & - & - & - & - & Geostationary & - & GEO-CAPE & USA & $>2022$ \\
\hline [21] & HyspIRI & 212 & $380-2500$ and $4000,7500-12,000$ & 30 & 185 & Sun-sync & 16 & HyspIRI & USA & $>2022$ \\
\hline
\end{tabular}


Radiometric resolution is defined as the minimum amount of radiance that each spectral band of a sensor can reliably measure, and it is determined by the way the data are digitally stored [26]. Other important radiometric capabilities include SNR and radiometric dynamic range. The dynamic range determines a sensors' ability to measure pixels of low radiance (e.g., over water) at the same time as ensuring that nearby bright pixels (e.g., over clouds) are not oversaturated [26].

The satellites in Table 1 are predominantly in a polar orbit, which means that on each orbit, they pass over the poles of the Earth and at a different location on the Equator, therefore covering all of the Earth over the course of their revisit time (the time it takes to return to over a specific location). Sun-synchronous orbits maintain a constant position in relation to the Sun, so that the monitored areas are illuminated consistently. On the other hand, geostationary satellites [84] constantly monitor a specific location on the Earth, as their orbits follow the speed and direction of the Earth's rotation. The first geostationary ocean colour satellite sensor, Geostationary Ocean Color Imager (GOCI) onboard the Korean Communication, Ocean and Meteorological Satellite (COMS), was launched in June of 2010 and has eight spectral bands from blue to NIR (412-865 nm) [116]. GOCI's hourly measurements during the daytime are a unique capability for short-term (e.g., diurnal variation) and long-term regional ocean environmental monitoring [117-119].

\subsection{Other Sensors}

The Multiangle Imaging Spectroradiometer (MISR) may complement ocean colour sensors by using nine cameras to sample a range of scattering angles and provide information about the particle concentrations of atmospheric aerosols. These include aerosol optical depth, the Angstrom exponent, aerosol type, the size and shape of particles and some information on single scattering albedo [120-123]. The Advanced Along Track Scanning Radiometer (AATSR) is another remote instrument that provides complementary data of clouds and aerosols that can be used in the atmospheric correction process [124]. Polarised light measurements show potential for aiding the atmospheric correction process $[125,126]$. POLDER is the only in-orbit sensor that captures both radiometric and polarimetric measurements [125]. POLDER uses a specific aerosol detection and atmospheric correction algorithm, Polarization-based Atmospheric Correction (POLAC) [125]. He et al. [126] demonstrated the potential for polarised patterns of light to provide useful additional information that can complement the data captured by spectral imagers in order to better understand atmospheric effects. Through a simulation, polarised light was shown to decrease the effects of sun glint and increase the TOA signal [126].

\section{Sensors: Outlook}

A number of reports have outlined requirements for future ocean colour sensors $[91,127,128]$ and provided insight into the potential capabilities of future hardware. These included reports by the IOCCG [128] and NASA [127], which detailed desirable future ocean colour sensor specifications, and a report by NASA in preparation for the Pre-Aerosol, Clouds and Ocean Ecosystem (PACE) mission [91]. These reports suggest that future space-based sensors will possess enhanced spectral, spatial, radiometric and temporal resolutions [91].

\subsection{Sensor Resolutions}

A recent review provides examples of the spectral, spatial, radiometric and temporal resolutions required for future sensors for various ocean colour applications [46]. Future hyperspectral sensors include Precursore Iperspettrale della Missione Operativa (PRISMA) [129], the Hyperspectral Imager Suite (HISUI) [130], the Environmental Mapping and Analysis Program (EnMap) [89], the Hyperspectral Infrared Imager (HyspIRI) [21] and the Ocean Radiometer for Carbon Assessment (ORCA), which is a prototype being designed to meet the requirements of NASA's Aerosol-Cloud-Ecosystem (ACE) and PACE missions [131]. These sensors possess high spatial and spectral resolutions, including SWIR bands with a SNR high enough to validate the black pixel assumption (see Section 6.1 for a definition) over turbid waters [132]. One drawback 
is the temporal resolution they provide, which is always more than a few days and, therefore, inadequate for certain applications, such as monitoring algal blooms [114]. Another issue is the lack of global collaboration between satellite missions, and the ocean colour community could benefit from missions working together by sharing data and ensuring there are no gaps in data collection between missions.

The mission PACE seeks to determine how much aerosol-type data are required to greatly improve atmospheric correction for retrievals and to discover when and where this information is most important [91]. The recommendations for the mission as set out in the report indicate a 5-nm spectral resolution between 350 and 800, with bands for atmospheric correction in the NIR (865 $\mathrm{nm}$ and either 820 or $940 \mathrm{~nm}$ ) together with the SWIR bands 1240, 1640 and $2130 \mathrm{~nm}$ [91]. A band in the near ultraviolet (UV) at $350 \mathrm{~nm}$ was also recommended. Bands in the near UV can be used to characterise concentrations of CDOM [133,134] and nitrates [38], as well as being useful in accounting for absorbing aerosols in the atmospheric correction process [135]. The PACE report also recommended a spatial resolution of $1 \mathrm{~km}$ and a revisit time of two days [91]. However, this limited spatial resolution makes it unsuitable for detailed characterisation of complex inland and coastal waters [136].

Data collected from hyperspectral airborne missions are particularly enlightening as to what can be expected from future satellite hyperspectral imagers. PRISM offers high SNR (500:1 at $450 \mathrm{~nm}$ ) and spectral resolution in the 380-600 nm range, which is useful for chlorophyll measurements [137,138]. Data collected with PRISM was also used to demonstrate the possibility of discriminating floating vegetation, such as seagrass and Sargassum based on spectral signature [139]. In the period 2013-2015, the HyspIRI Airborne Campaign collected data from five flights over California using AVIRIS and the MODIS/ASTER Airborne Simulator (MASTER) from a high altitude platform (NASA ER-2) to simulate the data that would be acquired by HyspIRI and to determine its appropriate sensor resolutions $[138,140]$. Various teams have explored the potential of HyspIRI to monitor inland waters and wetlands $[26,136,141]$, coastal waters $[139,142,143]$ and the open ocean $[138,144]$. A study was also conducted to assess whether HyspIRI data could enable improvements to the Atmospheric Removal Program (ATREM) atmospheric correction method [145]. Contributions included changes to gas absorption coefficients and taking into account liquid and ice absorption for the task of water vapour estimation [145]. As the focus of this study was atmospheric correction over land regions, there were no suggestions on the potential for HyspIRI to improve atmospheric correction methods over water.

Remote sensing of freshwater ecosystems can be problematic as they are often small and contain complex biophysical properties and, therefore, require sensors with high spatial and spectral resolutions [26]. The required spectral resolution for this task is addressed with the specifications of HyspIRI [26]. A spatial resolution of $60 \mathrm{~m}$ may not be enough to distinguish the diversity encountered in certain wetland regions and phytoplankton populations [26]. This spatial resolution enables the characterisation of $90 \%$ of freshwater ecosystems in Europe, but less than $20 \%$ in Australia [26]. The initial sensor design has been updated, so a spatial resolution of $30 \mathrm{~m}$ is now expected [141]. However, even a $30-\mathrm{m}$ resolution is inadequate when waters contain certain buoyancy regulating phytoplankton (e.g., cyanobacteria), as their distribution leads to underestimation of chlorophyll levels [146]. The major limitation with HyspIRI is the revisit time of 16 days, which is further extended when cloudy days are taken into consideration. This makes the mission only suitable for monitoring slow changing processes that can be characterised on a seasonal or annual basis and is therefore unsuitable for the characterisation of harmful algal blooms [26,136]. The radiometric resolution, in particular the high dynamic range and SNR proposed for HyspIRI, is particularly appropriate for inland waters [26]. The advantages of this mission are its global coverage and the fact that its data will be made publicly available, so it will be well suited to a range of applications and end users [26].

Monitoring giant kelp is currently challenging as these algae are highly dynamic in comparison to many primary producers that create habitats [142]. A spectral index was developed to assess 
the physiological condition of kelp fronds based on chlorophyll- $a$ and carbon ratios. It was able to explain $76 \%$ of observations from aircraft observations collected by AVIRIS as part of the HyspIRI Airborne Campaign [142]. The majority (96\%) of kelp patches are smaller than $3600 \mathrm{~m}^{2}$ [147]. The spectral and spatial resolution of HyspIRI will be suitable to monitor the seasonal variation in giant kelp populations, and the revisit time is sufficient to observe global kelp habitats cloud free at least once per seasonal cycle [142]. Measuring pelagic (open water) Sargassum remotely is challenging. The increased spectral resolution of HyspIRI will enable the characterization of Sargassum apart from spectrally-similar floating materials, such as Trichodesmium (filamentous cyanobacteria), Syringodium (sea grass), Ulva (sea lettuce), refuse and emulsified oil [143]. This study [143] assumed the initial design of the sensor with a 60-m spatial resolution together with an SNR of 200:1. Through the use of spectral unmixing, these resolutions would permit the observation of Sargassum patches that are more than $1 \mathrm{~m}$ wide and over $180 \mathrm{~m}$ long [143]. HypsIRI would be unable to monitor small-scale patches of Sargassum [143].

The characterisation of phytoplankton functional types (PFTs) in the complex waters of coastal regions is important for the detection of harmful algal blooms [148]. Phytoplankton detection with optics (PHYDOTax) is an algorithm that can determine PFTs from spectral shape information in the visible spectrum [138]. Two commonly-used atmospheric correction algorithms (ATREM [149] and Tafkaa [109]) were unable to provide adequate input to PHYDOTax in order to measure PFTs and chlorophyll- $a$ in Monterey Bay (Pacific coast, USA) [138]. A version of ATREM modified by using the OC3 (Ocean Color 3) chlorophyll- $a$ algorithm was able to measure chlorophyll- $a$, but not PFTs from PHYDOTax [138]. These findings suggest that sensor improvements are required to enable the measurement of PFTs, such as optimising the SNR in the blue-green range [105], as well as improving the SNR and spectral resolution in the 380-600-nm range, which is useful for chlorophyll measurements [138].

Geostationary mounted sensors, such as GOCI [84,116], are likely to become more prevalent in the future with GOCI-II planned for launch in 2018 [92] and NASA's Geostationary Coastal and Air Pollution Events (GEO-CAPE) mission due for launch after 2022 [93]. The GEO-CAPE mission will provide high spectral, spatial, radiometric and temporal resolution, although as it will be positioned in a geostationary orbit, it will provide only products for the Americas, not global coverage [101,150]. Geostationary satellites can form data of a much higher temporal resolution because they capture images every couple of hours, whereas satellites in a polar orbit revisit the same place once every few days [117-119]. These extra data can be exploited in order to avoid problems associated with clouds and to gain insights into ocean diurnal variations (e.g., the tidal process). Geostationary orbits may bring new challenges for atmospheric correction, for example problems associated with high solar-zenith angles at late afternoon measurements, which increase the distance through air between the Earth's surface and the sensor. In addition, highly turbid water in GOCI's covered ocean regions may still be an issue, in particular as GOCI lacks SWIR bands. Wang et al. [151] developed an atmospheric correction algorithm for GOCI based on the MODIS SWIR-derived NIR ocean colour data, and the GOCI-derived ocean colour data were shown to be quite reasonable [119].

\subsection{Other Sensors}

We may see an increase in the amount of ground-based sensors, such as AERONET, Maritime Aerosol Network and Bio-Argo floats. This would provide data to more regions, which could aid in vicarious calibration and the atmospheric correction process. These instruments require an increased spectral resolution and SNR to be useful for comparisons with hyperspectral remote measurements, and novel in situ sensors are required that are able to measure the spectral characteristic of backscattering [46]. Previous studies have demonstrated that there may be some advantages to making use of polarisation measurements for getting aerosol information [125,126]. In light of this, we may see future sensors equipped with this capability. The Second Generation Global Imager (SGLI) aboard the Global Change Observation Mission-Climate (GCOM-C) satellite, which is due to launch 
in early 2017, will be equipped with two multi-directional polarisation channels [87]. The polarimeter can be set at angles of $0^{\circ}, 60^{\circ}$ and $120^{\circ}$ and moved up to $45^{\circ}$ along the direction of the track, therefore allowing the instrument to extend its ability to capture the polarised aerosol signal. The ACE mission has recommended making use of a polarimeter [90], and the PACE mission has recommended the inclusion of a multispectral, multi-directional, multi-polarisation (3M) imager to enhance retrievals of aerosol optical depth and absorption [91].

\section{Contributions to the Top-of-Atmosphere Signal}

Figure 2 displays the radiances reaching a sensor at different distances from the water and was generated by a radiative transfer simulation [152]. The plot shows that the contribution of atmospheric effects increases with distance.

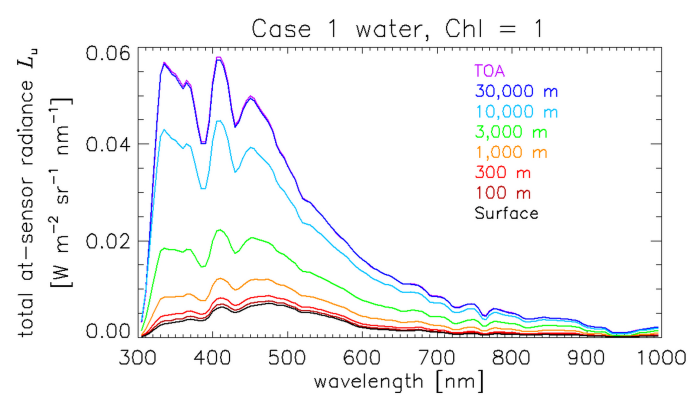

Figure 2. At-sensor radiances for a variety of altitudes. Increasing the altitude leads to an increase in the deterioration of the signal due to the atmospheric effects, which demonstrates the importance of accounting for the vertical distribution of aerosols (especially absorbing aerosols). The data were created with a radiative transfer simulation where the contributions of the surface effects and water-leaving radiance remained constant for all of the sensor altitudes [152]. Figure courtesy of C. Mobley, Ocean Optics Web Book [152].

Figure 3 shows the at-sensor radiance from Figure 2 at a distance of $3000 \mathrm{~m}$ divided into the contributions from the water-leaving radiance, the surface reflectance and the atmosphere. To calculate the water-leaving radiance, it is necessary to factor out the other contributions. In this section, we review atmospheric contributions with a specific focus on aerosols (as they are highly variable and therefore difficult to characterise), water surface effects and other corruptions to the signal.

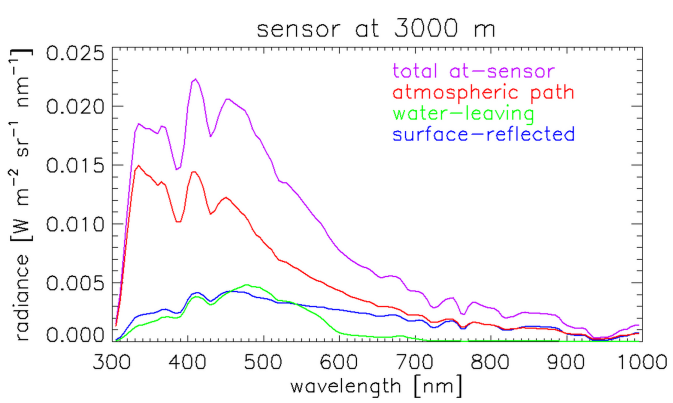

Figure 3. At-sensor radiance for a sensor at $3000 \mathrm{~m}$, divided into the contributions from the atmospheric effects, surface effects and water-leaving radiance. Retrieving the water-leaving radiance is often the principle goal of ocean colour remote sensing, and as it is only a relatively small percentage of the total contribution, it is important to accurately estimate the other factors that deteriorate the signal. The data were created with a radiative transfer simulation [152]. Figure courtesy of C. Mobley, Ocean Optics Web Book [152]. 


\subsection{Atmospheric Contributions}

The contributions of the atmosphere to the signal consist of the absorption of major gases, water vapour, Rayleigh scattering and aerosol effects [27,30]. Radiative transfer equations are used to create detailed models which account for the radiative transfer of light through the atmosphere $[27,29,30]$. The absorption coefficients of the major gases (oxygen, ozone, carbon dioxide, methane and nitrous oxide) in the atmosphere are well understood and can be simulated by taking into account atmospheric pressure, temperature, and solar and sensor geometry $[27,30,153]$. The effects of water vapour can be simulated on a pixel-by-pixel basis by making use of specific absorption bands (depending on those that are available from the sensor [154]). Rayleigh scattering can be estimated from the solar and sensor geometry, wind speed and atmospheric pressure [155-158]. As aerosols are spatially and temporally variable, the accurate retrieval of aerosol effects is often the most critical step in the atmospheric correction pipeline.

The optical properties of atmospheric aerosols can be classified in terms of their aerosol optical depth, Angstrom exponent, single scattering albedo, phase function and size distribution [27,30,159]. Early aerosol models were developed by Shettle and Fenn [160], who categorised different aerosol types into oceanic, maritime, tropospheric and urban with varying amounts of relative humidity. Gordon and Wang [27] made use of the maritime and tropospheric models of Shettle and Fenn for the open ocean and introduced an aerosol model specifically for coastal waters, which is $99.5 \%$ tropospheric and $0.5 \%$ oceanic. Moulin et al. [161] later introduced a dust model, which, together with the urban category, included strongly-absorbing aerosols that pose problems for atmospheric correction algorithms based on the black pixel assumption (see Section 6.1 for a definition).

The availability of data from AERONET has paved the way for the creation of aerosol models [159,162]. Ahmad et al. [159] developed a model for the ocean colour sensors, SeaWiFS and MODIS. The model takes into account eight variations of relative humidity $(95 \%, 90 \%, 85 \%$, $80 \%, 75 \%, 70 \%, 50 \%$ and $30 \%$ ), as well as 10 variations on how fine or coarse the particles are, resulting in a total of 80 variants [159]. The model has been shown to improve the accuracy of aerosol optical depth and the Angstrom exponent in comparison to previous models. However, retrievals of normalised water-leaving radiance were not significantly different from older models, and this is because atmospheric correction is the correction for the aerosol radiance and not aerosol optical properties. In fact, some new results show that reasonable ocean colour products can be derived without using aerosol models at all in atmospheric correction [163].

A number of atmospheric correction methods, such as the spectral optimisation algorithm (SOA) [164,165] and the NeuroVaria (neuro-variational) method [166,167], have made use of a simple model that uses a Junge power-law distribution to characterise the size of aerosol particles, together with a complex refractive index that is wavelength independent. For the spectral optimisation algorithm, the diameter of the particles is $D$, and $d N$ is the number of particles per unit volume in the size interval $D \pm d D / 2[164]$ :

$$
\begin{aligned}
\frac{d N}{d D}=K, & D_{0}<D \leq D_{1}, \\
=K\left(\frac{D_{1}}{D}\right)^{v+1}, & D_{1}<D \leq D_{2}, \\
=0, & D>D_{2} .
\end{aligned}
$$

The values of $D_{0}, D_{1}$ and $D_{2}$ were set as $0.06 \mu \mathrm{m}, 0.2 \mu \mathrm{m}$ and $20 \mu \mathrm{m}$, respectively. The six values for size parameter $v$ were chosen at intervals of 0.5 between 2.0 and 4.5 [164]. As models based on the Junge power-law distribution do not require a comprehensive set of in situ measurements, they have the potential to be applied universally. One limitation of these simple models is that they assume that the particles are spherical, which does not accurately account for the diversity of aerosol particles [165]. 


\subsection{Water Surface Effects}

Water surface issues include sun glint, ocean surface reflection, sky glint, whitecaps or surface foam. Ideal conditions for ocean colour remote sensing are a relatively low solar- and sensor-zenith and avoiding sun glint [30].

The magnitude of the contribution from whitecaps and surface foam is principally reliant on wind speed [168-171]. However, other influences include air and water temperature, fetch, salinity and surface tension [170]. Wind speed is used to calculate the influence of whitecaps (based on the model of Koepke [169]) and the influence of sun glint (using the model of Cox and Munk [172]). Wind speed data from the National Center for Environmental Prediction (NCEP) has been used from SeaWiFS (1997) for all NASA ocean colour missions [173]. However, all this data has a temporal resolution of six hours, and variations from the average will lead to inaccurate atmospheric correction and, therefore, errors in the retrievals of bio-optical water properties. Satellite-mounted scatterometers are capable of taking accurate measurements of wind speed at the ocean surface [174], and their widespread use could be adopted so that wind speed measurements are captured simultaneously with spectral data and can be input to sun glint and whitecap models. However, it was found that the whitecap radiance contribution at the TOA is not as important as originally thought [170].

Sun glint occurs when sunlight reflects off the surface of the water into the field of view of the sensor $[172,175,176]$. The factors that can affect sun glint are the relative position of the Sun and sensor, as well as cloud cover and wind speed (as rougher surfaces create more angles for the light to reflect off) [177]. To avoid sun glint, the viewing angle of the sensor can be changed (e.g., in SeaWiFS [163], CHRIS [178] and Hyperion [179]), and sensors located on satellites in a geostationary orbit can deal with sun glint by only capturing in sun glint free windows. Wang and Bailey [175] developed a sun glint correction algorithm, which has been used for ocean colour and aerosol products for SeaWiFS, MODIS and VIIRS. Zhang and Wang [176] showed that the Cox and Munk model [172] is still the best one to use. Simulations have demonstrated the usefulness of polarised light measurements for the task of estimating sun glint contamination $[126,180]$. Approaches to detect sun glint include labelling high values of water-leaving radiance as contaminated [181] and calculating the ratio between bright and dark pixels through histogram analysis [177]. The spectral matching approach, Polynomial-based algorithm applied to MERIS (POLYMER), models sun glint with a polynomial [163]. The Complex Water Atmospheric Correction Algorithm Scheme (CAAS) derives both aerosol and sun glint contributions directly from knowledge of the total and Rayleigh-corrected radiances [182]. A cloud removal method developed for HICO can be applied to the removal of sun glint [104]. Sun glint has also been shown to be beneficial for certain applications, having been used to calculate water vapour levels [183], absorbing aerosols [184] and to calibrate the spectral bands of a sensor [185].

\subsection{Clouds and Adjacency Effects}

Clouds and adjacency effects are other factors that can contaminate the top-of-atmosphere signal. Cloud masking using the NIR and SWIR methods for ocean colour data processing are quite robust (e.g., used for routine global ocean colour productions from SeaWiFS, MODIS and VIIRS) [186,187]. In particular, the SWIR cloud masking approach has significantly improved ocean colour results for turbid coastal and inland waters [187]. Geostationary sensors can largely deal with the problems of sun glint and clouds by only capturing in the appropriate sun glint- and cloud-free windows [96]. MISR has been used for cloud masking [188], as has the POLDER sensor, which uses a band at $865 \mathrm{~nm}$ and masks clouds on the assumption that they are spatially less homogeneous than water and aerosols [189].

Supervised methods have been used in the task of cloud detection, such as discriminant analysis [190], support vector machines [191] and neural networks [192]. Unsupervised classification has been applied to this task using features such as brightness, whiteness, oxygen and water vapour 
absorption [193]. Hyperspectral sensors have shown an increased ability over multispectral sensors to determine important characteristics for the analysis of clouds [194,195]. A number of cloud detection methods have been proposed for hyperspectral sensors [104,196]. Gomez-Chova et al. [196] made use of spectral derivative analysis. Based on the observation that clouds are both bright and white, a cloud can be detected by searching for pixels with high intensity values (bright) and low values in the first derivative of the spectral signal (white) [196].

Another unsolved problem in ocean colour remote sensing is how to deal with adjacency effects in the data (the contribution from neighbouring pixels). This often occurs next to bright areas in a scene, such as land or clouds, and can lead to uncertainties in the TOA signal. Adjacency effects are often taken into account in the atmospheric correction step through taking the average of neighbouring pixels [197,198], modelling the effect with a Monte Carlo simulation [199] and treating adjacency effects as a spectral unmixing problem [200]. The Improving Contrast between Ocean and Land (ICOL) processor, developed specifically for MERIS, applies a pre-processing step to correct for adjacency effects before correcting for atmospheric effects [201]. This is achieved by taking into account the coupling between Fresnel reflection and Rayleigh scattering [202]. Different studies evaluating this method have shown both positive and negative results [203]. Similarity Environment Correction (SIMEC) makes use of the NIR spectral similarity method and, although originally developed for hyperspectral imagery [204], has now been adapted to be sensor generic [203].

\section{Multispectral Approaches for Atmospheric Correction}

\subsection{Black Pixel Approaches}

The approach that makes an assumption of black pixels at the NIR wavelengths is the most widely-used aerosol retrieval technique [27]. This method assumes there is no water-leaving radiance contribution in the NIR bands and, therefore, any measurements taken from NIR bands in these regions are representative of atmospheric and ocean surface effects. Firstly, the aerosol effects are calculated and compensated for, which leaves the estimates of water-leaving radiance. Secondly, a constituent retrieval algorithm uses the water-leaving radiance to calculate the different concentrations of water constituents, such as chlorophyll and CDOM [27]. In coastal regions or inland waters, the NIR black pixel assumption often fails. This can be due to turbid waters, which contain high concentrations of suspended particles resulting in non-negligible water-leaving radiance contributions at the NIR bands $[43,110,111,152,205]$.

Many modifications have been made to the black pixel approach. The standard NASA method [206] (an improvement to the revised NIR algorithm of [205]) makes use of an optical model to estimate the normalised water-leaving radiance in the NIR bands to improve atmospheric correction over turbid waters. Ruddick et al. [110,207] developed the NIR spatial homogeneity algorithm (MUMM, named after the institute where it was developed, the Management Unit of the North Sea Mathematical Models), which assumes that a spatial homogeneity exists in the ratios of two NIR bands. An approach for GOCI is based on a regional (Western Pacific) empirical relationship between the water-leaving radiance in the NIR and the diffuse attenuation coefficient at $490 \mathrm{~nm}$ [151]. Another method, BMW (Bailey, MUMM, Wang) [208] is a combination of the standard NASA method [205,206], the MUMM algorithm [110,207] and the empirical approach of Wang et al. [151]. Through building upon the advantages of each algorithm, it is able to show an improved performance over the original algorithms [208].

An alternative technique makes use of MODIS Aqua SWIR bands at 1240, 1640 and $2130 \mathrm{~nm}$, as the black pixel assumption is mostly valid for these bands in turbid waters $[39,209]$. The SWIR approach has fundamentally resolved the black pixel assumption issue for atmospheric correction over turbid coastal and inland waters [29]. In fact, the SWIR-based atmospheric correction algorithm has been successfully used for accurately deriving ocean colour products over highly turbid coastal and inland waters for various applications $[9,10,33,210-216]$. However, the low SNR in the SWIR bands is a major limitation [203]. Wang and Shi [217] have improved the MODIS SWIR SNR 
performance for ocean colour data processing by using spatially averaged (e.g., $5 \times 5$ grid) SWIR data. The SWIR improvement algorithm [217] has also been implemented in the VIIRS ocean colour data processing for routine ocean colour production with the SWIR approach. Chen et al. [218] improved upon the SWIR method and decreased mean root mean square error by $14.21 \%-42.7 \%$. This was achieved by calculating the aerosol reflectance and type from a cross-calibration process that makes use of a $5 \times 5$ grid of pixels from less turbid waters. A method developed for MODIS corrects for the contributions from suspended sediments in the Rayleigh-corrected radiance at $748 \mathrm{~nm}$ and then uses this value to estimate the aerosol contribution at $531 \mathrm{~nm}$ [219]. This technique might show some benefits over the turbid waters off the south coast of India [219]. A summary of atmospheric correction approaches that make the black pixel assumption can be seen in Table $2[39,110,151,206-209,217,218,220,221]$.

Table 2. Black pixel assumption approaches for atmospheric correction. These atmospheric correction methods make an assumption of zero water-leaving radiance in specific bands. Values in these bands are taken as an estimate of the atmospheric contributions to the top-of-atmosphere signal. (Key. Bands: bands assumed black; NIR, near infrared; SWIR, shortwave infrared. Conditions: conditions the method can handle in addition to the open ocean; TW, turbid waters; AA, absorbing aerosols; SNR, signal-to-noise ratio; MODIS, Moderate Resolution Imaging Spectroradiometer; SeaWiFS, Sea-viewing Wide Field-of-View Sensor.)

\begin{tabular}{|c|c|c|c|}
\hline Ref. & Bands & Conditions & Comments \\
\hline [206] & NIR & - & Optical model estimates normalised water-leaving radiance in the NIR bands \\
\hline [151] & NIR & - & $\begin{array}{l}\text { Based on a regional (Western Pacific) empirical relationship between the } \\
\text { water-leaving radiance in the NIR and the diffuse attenuation coefficient at } 490 \mathrm{~nm}\end{array}$ \\
\hline [208] & NIR & - & $\begin{array}{l}\text { Improves performance by building upon the advantages of three methods }[151,206,207] \\
\text { (e.g., aerosol reflectance ratios between two NIR bands are locally derived) }\end{array}$ \\
\hline$[39,209]$ & SWIR & TW & $\begin{array}{l}\text { Resolves the black pixel assumption issue for atmospheric correction over turbid } \\
\text { coastal and inland waters; limited by low SNR in SWIR bands of current sensors }\end{array}$ \\
\hline [218] & SWIR & TW & $\begin{array}{l}\text { Cross-calibration process uses a } 5 \times 5 \text { grid of pixels from less turbid waters to } \\
\text { calculate aerosol reflectance and type }\end{array}$ \\
\hline [220] & SWIR & AA & $\begin{array}{l}\text { Estimate of water-leaving radiance in the } 412-\mathrm{nm} \text { channel of SeaWiFS constrains } \\
\text { the aerosol retrieval model }\end{array}$ \\
\hline [221] & NIR/SWIR & TW/AA & $\begin{array}{l}\text { Uses pre-atmospheric correction step to find pixels corresponding to turbid waters } \\
\text { or absorbing aerosols }\end{array}$ \\
\hline
\end{tabular}

\subsection{Spectral Inversion Approaches}

Spectral inversion approaches simultaneously retrieve bio-optical water properties and correct for atmospheric effects in one step [165,222]. The spectral optimisation algorithm (SOA) $[164,165]$ employs a simple aerosol model which determines the size of aerosol particles with a Junge power-law distribution. This distribution is a simplification, which enables SOA to achieve optimisation when there are a limited number of spectral bands [223]. This algorithm's performance was demonstrated when it was used for atmospheric correction of turbid waters on a synthetic dataset [224] and on SeaWiFS data in a case study of Chesapeake Bay (Atlantic coast, USA) [223].

Other spectral inversion methods include certain neural network models developed, for example, to derive concentrations of phytoplankton, detritus and CDOM from MERIS data for a variety of water types, including highly turbid waters $[225,226]$. This method is also able to output the aerosol concentration in a scene. The standard atmospheric correction product used with MERIS for turbid coastal and inland waters is the Case-2 Regional Processor (C2R) [227], which makes use of a neural network. More recently, a novel neural network technique applied fuzzy c-mean clustering and showed an improvement over C2R in its ability to retrieve chlorophyll- $a$ in the coastal waters of northwest Spain [228]. 


\subsection{Absorbing Aerosols}

Absorbing aerosols, such as smoke, dust and pollution, often occur over land and in coastal areas and have proven difficult to account for in the atmospheric correction process. The infrared bands, which are used for the aerosol retrievals in all of the approaches that make use of the black pixel assumption $[39,206]$, are unable to capture any information in regards to the presence of absorbing aerosols. Oo et al. [220] developed a SWIR atmospheric correction method for over coastal regions with varying aerosols (especially absorbing aerosols) which made use of an estimate of water-leaving radiance in the 412-nm channel of SeaWiFS to constrain the aerosol retrieval model. Improvements were demonstrated in comparison to SWIR and NIR retrievals from SeaWiFS Data Analysis System (SeaDAS) over Chesapeake Bay in conditions of absorbing aerosols. Other methods have been developed that are not based on the black pixel assumption, such as the spectral optimisation algorithm, which has been shown to deal well with pollution-type absorbing aerosols [222].

NeuroVaria models the radiative transfer of atmospheric and oceanic properties with a neural network, and a variational algorithm (second-order gradient-descent) is used for the spectral inversion $[229,230]$. Later developments to the approach enabled absorbing aerosols to be modelled with a Junge power-law distribution [166,167]. NeuroVaria has also shown promise at dealing with turbid waters by making use of five NIR bands to correct for atmospheric effects, although the results displayed underestimated water-leaving radiance in the short-wavelength parts of the spectrum (412-443 nm) [231].

The spectral matching algorithm (SMA) $[27,161]$ is another spectral inversion atmospheric correction algorithm. SMA is not reliant on the black pixel assumption and is able to account for strongly-absorbing aerosols (specifically dust, as this has a wavelength-dependent refractive index [222]). The results from a study of SeaWiFS data in the Mediterranean showed that the SMA approach did not produce better water-leaving radiance retrievals than the NASA standard NIR method [27] when dust was present, but only when it was the dominant aerosol [222]. This suggests that SMA should only be used when a pixel has been identified as being dominated by dust. Another reason the approach should be used only in this way is the fact that it produces errors if the aerosol model contains both non-absorbing and strongly-absorbing aerosols, so a pre-atmospheric correction step is required to garner knowledge of the location of specific aerosol types [222]. There are no approaches that are able to characterise all types of absorbing aerosols that occur, and this may be due to a lack of accurate aerosol models. The spread of ground-based sensors, such as AERONET, will permit the characterisation of more aerosol types from more regions [232].

When accounting for absorbing aerosols, knowledge of their vertical distribution is required due to the effects of multiple scattering [222]. Novel sensors that capture LiDAR, polarimetric or near UV measurements will aid the characterisation of this distribution. NASA is currently retrieving this information from LiDAR measurements aboard Cloud-Aerosol LiDAR and Infrared Pathfinder Satellite Observations (CALIPSO) [233,234], which trails MODIS Aqua. A limitation with this approach is that LiDAR measurements are only able to capture one vertical measurement, and the rest of the scene must be estimated from this single measurement. Therefore, it is necessary to make an assumption that absorbing aerosols are uniform across a scene, which is often invalid. For future missions (ACE), it has been recommended that a "curtain" of LiDAR measurements should be captured together with measurements of polarised radiance in order to accurately capture the single scattering albedo and vertical distribution of aerosols [90]. We may also see future sensors that combine hyperspectral and LiDAR measurements [235]. The Second generation GLobal Imager (SGLI) includes a multi-directional polarimeter, which will greatly enhance the ability to characterise the polarised aerosol signal and also has a band at $380 \mathrm{~nm}$ [87]. The near UV part of the electromagnetic spectrum is highly sensitive to the influence of absorbing aerosols, having been measured using a band at $380 \mathrm{~nm}[236,237]$. He et al. [135] proposed an atmospheric correction method that uses the near UV bands, and this was even shown to work on a band in the blue part of the spectrum $(412 \mathrm{~nm})$. Sensing in the near UV part of the spectrum would greatly aid in the 
correction of absorbing aerosols, and for future missions (PACE) it is planned to include bands down to $350 \mathrm{~nm}$ [91]. Measurements of water-leaving radiance in the near UV bands are also useful for discriminating between chlorophyll- $a$ and CDOM [90].

\subsection{Multi-Purpose Approaches}

Here, we outline approaches that show the potential for dealing with the current challenges for atmospheric correction. A number of methods make use of a pre-atmospheric correction step to identify specific pixels which may require alternative correction techniques [221,238]. Moore et al. [238] developed an approach that flags pixels where the black pixel assumption is unlikely to be valid. Single scattering aerosol reflectance and surface reflectance are then iteratively determined from the flagged pixels with a coupled hydrological and atmospheric model in the NIR [238]. Shi and Wang [221] developed a technique that makes use of a pre-atmospheric correction step to estimate the areas in a scene that contain turbid waters and absorbing aerosols, so that specific atmospheric correction approaches that are better able to handle these conditions can then be used. Firstly, turbid waters are detected using the NIR and SWIR bands, and secondly, the short-visible and NIR bands are used to identify absorbing aerosols [221]. This pre-correction step would work well if there were approaches that are able to correct for the absorbing aerosols that are specific to local regions where unique atmospheric conditions occur.

Some promising algorithms for multispectral sensors that have shown some progress at dealing with complex waters and absorbing aerosols are POLYMER [163] and the ENLF model [239]. POLYMER is a spectral matching approach that has been proposed primarily to deal with sun glint [163]. This method makes use of a model of both water-leaving radiance and the spectral signal of the atmosphere in which sun glint is modelled with a polynomial [163]. POLYMER shows a large improvement for retrievals in sun glint regions of MERIS data in comparison to the operational atmospheric correction algorithm of MERIS and similar results in regions free of sun glint [163]. Measurements could be captured in sun glint regions with a specular reflectance as bright as $20 \%$ and resulted in only a $15 \%$ reduction in the accuracy of the retrievals [163]. The advantages of this technique are that it does not make a black pixel assumption or include an aerosol model, both of which have been shown to create errors in other methods. Suggestions for future improvements include adding a more accurate model of the atmosphere and including a free parameter that can account for the absorption effects of certain aerosols [163].

Mao et al. [239] have opened up the possibility of a universal atmospheric correction algorithm (ENLF) that makes an assumption of aerosol scattering reflectance that is based on the Angstrom law rather than the black pixel assumption and is therefore valid for situations when black pixel approaches fail. A look-up table containing in situ measurements of water-leaving reflectance is used to determine the aerosol scattering reflectance with a non-linear least squared fit function. This reflectance is used to estimate aerosol single scattering reflectance and, following this, epsilon values are determined [239]. The main limitation with ENLF is its reliance on accurate look-up-tables (both ocean and land) that contain in situ data that are representative of the study site [239].

\section{Hyperspectral Approaches for Atmospheric Correction}

Following experiments with airborne hyperspectral imagery, it was found that an increase in temporal, spectral and spatial resolution was required in order to monitor the dynamics of turbid coastal waters [96]. Davis et al. [96] recommended a temporal frequency of three hours to be able to capture the influence of tides, winds, run off from rivers and algal blooms. This can be achieved with satellites in a geostationary orbit, although it is unlikely that complete global coverage will be achieved any time soon. In order to characterise complex coastal waters, a spatial resolution $<100 \mathrm{~m}$ was recommended [95,96]. However, studies as part of the HyspIRI Airborne campaign found that a spatial resolution of $60 \mathrm{~m}$ would be unsuitable for monitoring certain areas that contain diverse mixtures of phytoplankton, in particular in inland waters [26]. A spatial resolution of $30 \mathrm{~m}$ is now 
expected for HyspIRI [141], and this will enable the identification of small-scale turbidity features [99]. However, a 30-m resolution is still inadequate for inland and coastal waters that contain certain buoyancy regulating phytoplankton (e.g., cyanobacteria) [146].

Davis et al. [96] stated that a hyperspectral resolution was desirable, although no number of bands was suggested. Due to computational advances, previous issues, such as processing, transmitting and storing hyperspectral data, are becoming less restrictive. As the spectral signals in the natural world are predominantly broadband, the data in neighbouring channels are often redundant. One challenge is therefore to determine how much of the information is useful and how much is superfluous [240]. A number of studies have sought to determine the optimal number of bands for a spectral sensor for the task of ocean colour remote sensing and have suggested that the improvement in accuracy over $\sim 15$ bands is negligible [241,242].

Absorption from water vapour and nitrogen is highly variable and therefore difficult to adequately correct for in the atmospheric correction process [30]. The bands of multispectral sensors are placed so as to avoid the absorption bands of these gases. A challenge for hyperspectral atmospheric correction is to include these bands and to develop atmospheric correction techniques that take these contributions into account. Lee et al. [241] suggested that rather than attempting to accurately correct all of the hyperspectral data, multispectral bands should be used to reconstruct a hyperspectral signal. It was found that hyperspectral absorption spectra could be recovered from multispectral (CZCS and MODIS) measurements with 95\% accuracy [243].

\subsection{Spectral Inversion Approaches}

Spectral inversion methods and constituent retrieval algorithms using hyperspectral data have shown benefits over using multispectral measurements [102,244]. Semi-analytical inversion methods attempt to derive inherent optical properties, such as absorption and scattering coefficients, from apparent optical properties, such as normalised water-leaving radiance and remote sensing reflectance [36,242,245-247]. Hyperspectral data have been shown to reduce the ambiguity of these inversions [248] and the resulting bio-optical water properties [244]. Algorithms that build upon hyperspectral datasets may also be able to perform the retrieval of properties that are not currently possible, as well as retrieving multiple variables simultaneously rather than current algorithms that calculate one variable at a time [26].

In the open ocean, the main contribution to the colour of the water is phytoplankton, and band ratios (or difference) in the blue-green regions can be used to successfully retrieve levels of chlorophyll- $a[31,249,250]$. However, turbid waters are a complex mix of constituents, such as phytoplankton, CDOM and suspended particulate matter (SPM). Constituent retrieval algorithms for these waters need to make use of reflectance values in the red and NIR parts of the spectrum, as these regions are less affected by CDOM and SPM [114,215]. Although the majority of constituent retrieval algorithms for turbid waters have been developed for multispectral sensors and their estimates of chlorophyll- $a$ are poor [25], a recent method has shown some success at retrieving the chlorophyll- $a$ concentration in turbid waters [251]. The potential for hyperspectral sensors for monitoring chlorophyll- $a$ and phytoplankton in turbid coastal and inland waters has been demonstrated in a number of studies $[23,102,106]$. Specific bands of HICO were selected by the three-band model in accordance with the optical properties of the water [23,102]. Not only were accurate chlorophyll- $a$ estimates achieved, but the fine spectral detail allowed derivative spectroscopy to be applied, which revealed subtle features relating to concentrations of other phytoplankton pigments (e.g., phycoerythrin and phycocyanin) [23]. Figure 4 demonstrates how the absorption features of phycoerythrin, phycocyanin and chlorophyll- $a$ are missed with the multispectral bands of MERIS, but are revealed with the first derivative of a hyperspectral signal [23]. 

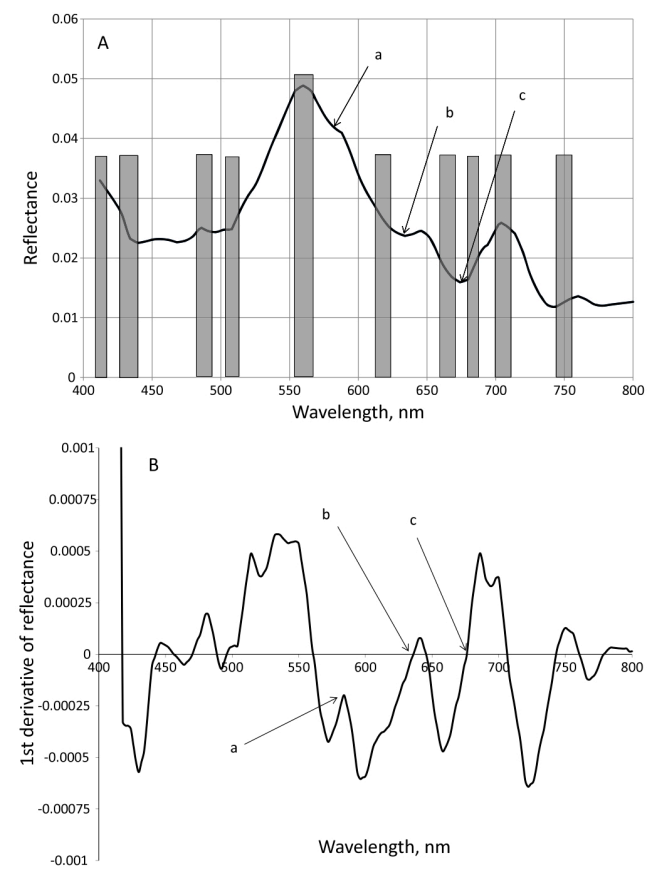

Figure 4. The detection of subtle absorption bands made possible with a hyperspectral resolution. (A) The median spectral reflectance of the turbid waters of the Azov Sea, Russia, is shown over the multispectral bands of MERIS; (B) The first derivative of the reflectance signal. The absorption bands of (a) phycoerythrin; (b) phycocyanin and (c) chlorophyll-a. Figure courtesy of A. A. Gitelson [23]. (c) IOP Publishing. Reproduced with permission. All rights reserved.

\subsection{Derivative Spectroscopy}

Derivative spectroscopy analyses the shape of spectral signals by enhancing subtle features [252]. As this technique is sensitive to noise, the spectral signals are firstly smoothed (with a technique such as Savitzky-Golay smoothing [22]). The n-th-order derivatives are computed with a finite difference approximation. A sampling window determines how much detail is taken from the signal. Derivative spectroscopy is a well-established method in the domains of pharmacology and medical biology [253]. An early attempt to apply this technique to atmospheric correction of remotely-sensed imagery was limited by the fact that it sought to develop an algorithm that would be completely insensitive to atmospheric effects [22,254]. Now that the importance of the atmospheric correction step is widely recognised, the application of derivative spectroscopy to the characterisation of atmospheric effects should be revisited.

Derivative spectroscopy has been used in a range of hyperspectral ocean studies to discriminate between healthy and unhealthy corals [255], to identify bottom types in shallow waters [256] and to classify different groups of phytoplankton $[252,257,258]$. A number of recent works have demonstrated the potential for this technique to analyse complex coastal waters $[259,260]$ and atmospheric effects such as thin cirrus clouds and aerosols [253]. Tufillaro and Davis [260] demonstrated image enhancement and feature selection applications of derivative spectroscopy applied to $\mathrm{HICO}$ for turbid coastal waters with riverine inputs. In an image of the Columbia river meeting the Pacific (northwest USA), the bands that were chosen to create a false colour image were selected from the extrema of the fourth derivative, which enhanced the differentiation of water types (Figure 5). In an image of the Yangtze River meeting the East China Sea (Shanghai, China), the second derivative was used to highlight features related to sediment reflectance (peak at $800 \mathrm{~nm}$ ) and algal blooms (peak at $710 \mathrm{~nm}$ ), the latter of which is not easily detectable in the original signal [260]. A recent study that applied derivative analysis of hyperspectral data to study atmospheric particles (cirrus clouds and aerosols) provides a glimpse into how this technique 
could improve the atmospheric correction process [253]. First and second derivatives of measured (ground-based) and modelled spectral signals displayed distinct spectral signatures, which could be used to classify aerosol types [253].
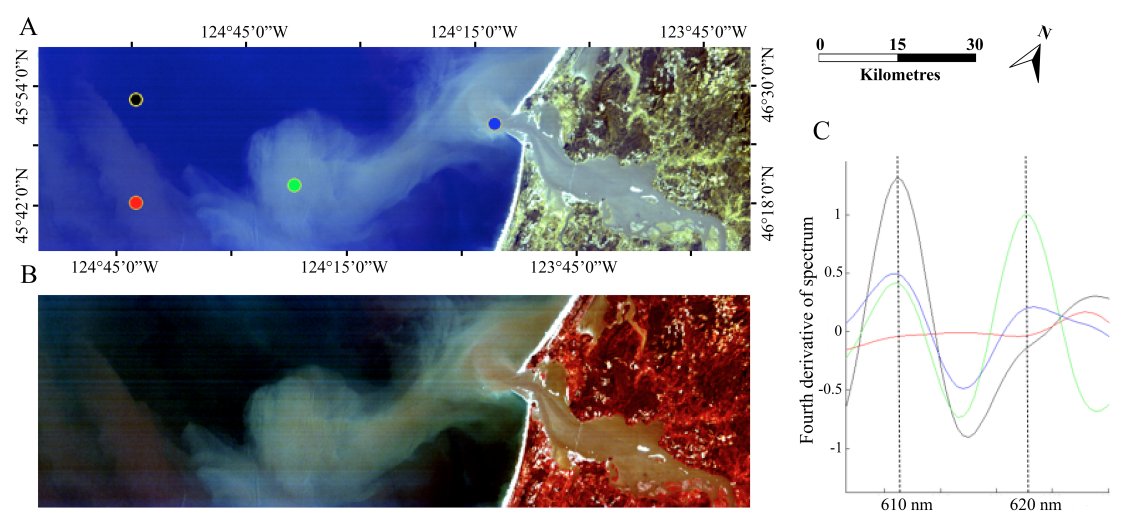

Figure 5. Image of the Columbia River meeting the Pacific (northwest USA) from HICO on 12 May 2012 at 1:05 GMT. (A) RGB image; (B) The plume structure is highlighted with the enhanced image; (C) Channels sensitive to plume sediments are selected using derivative analysis. Figure courtesy of N. B. Tufillaro [260]. Approximate scale, north arrow and coordinates.

\section{Conclusions}

The major unsolved challenges for the atmospheric correction of ocean colour remote sensing are encountered over turbid coastal and inland waters and in conditions where strongly-absorbing aerosols are present. These issues could be solved through the use of improved satellite-based sensors and atmospheric correction algorithms, which build upon these advancements. Sensors that include bands in the near UV [18,21,92] can aid the correction of absorbing aerosols [87,91], as well as the characterisation of CDOM concentrations [133,134]. A promising avenue for hyperspectral approaches is to adaptively choose which bands are most useful depending on the task or the optical properties of the water and atmosphere. Future hyperspectral sensors $[19-21,89]$ with bands up to the SWIR region (and an increased SNR in the SWIR bands) will be able to take advantage of a range of bands throughout the NIR and SWIR to selectively switch to the most efficient bands to be used to validate the black pixel assumption depending on the optical properties of the water (in a similar way to how HICO's NIR bands were used to select the most appropriate bands for a three-band chlorophyll retrieval algorithm [23,102]). Previous reliance on band-specific algorithms neglects the fact that hyperspectral data can be treated as a continuous signal rather than distinct independent variables. In order to be able to fully take advantage of hyperspectral data's potential for more accurate retrievals of biophysical properties (such as phytoplankton functional types [138]), it is important to develop appropriate atmospheric correction methods. One possibility is to make use of spectroscopic techniques such as derivative analysis [253].

Fusing data from multiple sources (e.g., AERONET, CALIPSO, POLDER, MISR and AATSR) is another promising direction for enhanced atmospheric correction solutions. Increased access to aerosol data (with polarimeters and LiDAR measurements capturing the vertical distribution of aerosols $[87,90,91]$ and extensions to the network of ground-based sensors $[55,67]$ characterising the spatial/temporal distribution of aerosols) has the potential to lead to the development of models that more accurately characterise regional and global variability [232]. Models such as those based on the Junge power-law could be extended to incorporate the variability of aerosol particles and, instead of existing in a discrete format, models of a continuous nature could be developed. Atmospheric correction methods without aerosol models [163] have also shown potential and require further exploration. 
Hyperspectral sensors HICO, PRISMA, HISUI and HyspIRI are designed with the recommended spatial resolution of $<100 \mathrm{~m}$ per pixel [96]. However, this may not be enough for certain locations that contain varied mixtures of phytoplankton [26]. Another limitation is that their revisit times are not adequate for many applications, such as monitoring algal blooms [114]. Geostationary sensors (e.g., GEO-CAPE) can address this issue, but global coverage remains a distant hope. In the future, we are also likely to see other useful technologies that can aid in the atmospheric correction process, such as sensors that combine hyperspectral and LiDAR data [235].

Acknowledgments: This work is supported by Queen Mary University of London's Engineering and Physical Sciences Research Council (EPSRC) Doctoral Training Centre EP/G03723X/1. The views, opinions and findings contained in this paper are those of the authors and should not be construed as an official NOAA or U.S. Government position, policy or decision.

Author Contributions: Simon Emberton reviewed the literature and drafted the first version of the article. Lars Chittka, Andrea Cavallaro and Menghua Wang all contributed to the writing of the published version of the manuscript.

Conflict of Interest: The authors declare no conflict of interest.

\section{References}

1. Goetz, A.F. Three decades of hyperspectral remote sensing of the Earth: A personal view. Remote Sens. Environ. 2009, 113, S5-S16.

2. Gordon, H.R.; Clark, D.K.; Mueller, J.L.; Hovis, W.A. Phytoplankton pigments from the Nimbus-7 Coastal Zone Color Scanner: comparisons with surface measurements. Science 1980, 210, 63-66.

3. McClain, C.R. A decade of satellite ocean color observations. Ann. Rev. Mar. Sci. 2009, 1, $19-42$.

4. Aumann, H.H.; Gregorich, D.T.; Broberg, S.E.; Elliott, D.A. Seasonal correlations of SST, water vapor, and convective activity in tropical oceans: A new hyperspectral data set for climate model testing. Geophys. Res. Lett. 2007, 34, L15813.

5. Nagendra, H.; Lucas, R.; Honrado, J.P.; Jongman, R.H.; Tarantino, C.; Adamo, M.; Mairota, P. Remote sensing for conservation monitoring: Assessing protected areas, habitat extent, habitat condition, species diversity, and threats. Ecol. Indic. 2012, 33, 45-59.

6. Hochberg, E.J.; Atkinson, M.J.; Apprill, A.; Andrefouet, S. Spectral reflectance of coral. Coral Reefs 2004, 23, 84-95.

7. Stephens, F.C.; Louchard, E.M.; Reid, R.P.; Maffione, R.A. Effects of microalgal communities on reflectance spectra of carbonate sediments in subtidal optically shallow marine environments. Limnol. Oceanogr. 2003, $48,535-546$.

8. Corson, M.R.; Lucke, R.L.; Davis, C.O.; Bowles, J.H.; Chen, D.T.; Gao, B.C.; Snyder, W.A. The Hyperspectral Imager for the Coastal Ocean (HICO) environmental littoral imaging from the International Space Station. In Proceedings of the IEEE Geoscience and Remote Sensing Symposium, Honolulu, HI, USA, 25-30 July 2010; pp. 3752-3755.

9. Shi, W.; Wang, M. Satellite views of the Bohai Sea, Yellow Sea, and East China Sea. Prog. Oceanogr. 2012, 104, 30-45.

10. Wang, M.; Shi, W.; Tang, J. Water property monitoring and assessment for China's inland Lake Taihu from MODIS-Aqua measurements. Remote Sens. Environ. 2011, 115, 841-854.

11. Emmerson, P.; Ross, H. Colour constancy with change of viewing distance under water. Perception 1985, 14, 349-358.

12. Skorupski, P.; Chittka, L. Is colour cognitive? Opt. Laser Technol. 2011, 43, 251-260.

13. Schaepman, M.E.; Ustin, S.L.; Plaza, A.J.; Painter, T.H.; Verrelst, J.; Liang, S. Earth system science related imaging spectroscopy-An assessment. Remote Sens. Environ. 2009, 113, S123-S137.

14. Hovis, W.A.; Clark, D.K.; Anderson, F.; Austin, R.W.; Wilson, W.H.; Baker, E.T.; Ball, D.; Gordon, H.R.; Mueller, J.L.; El-Sayed, S.Z.; et al. Nimbus-7 Coastal Zone Color Scanner: system description and initial imagery. Science 1980, 210, 60-63.

15. McClain, C.R.; Feldman, G.C.; Hooker, S.B. An overview of the SeaWiFS project and strategies for producing a climate research quality global ocean bio-optical time series. Deep Sea Res. Pt. II: Top. Stud. Oceanogr. 2004, 51, 5-42. 
16. Rast, M.; Bezy, J.L.; Bruzzi, S. The ESA Medium Resolution Imaging Spectrometer MERIS a review of the instrument and its mission. Int. J. Remote Sens. 1999, 20, 1681-1702.

17. Wang, M.; Liu, X.; Tan, L.; Jiang, L.; Son, S.; Shi, W.; Rausch, K.; Voss, K. Impact of VIIRS SDR performance on ocean color products. J. Geophys. Res. Atmos. 2013, 118, 10347-10360.

18. HICO. Available online: http://hico.coas.oregonstate.edu/ (accessed on 14 August 2015).

19. HISUI. Available online: https://directory.eoportal.org/web/eoportal/satellite-missions/a/alos-3 (accessed on 14 August 2015).

20. PRISMA. Available online: https://directory.eoportal.org/web/eoportal/satellite-missions/p/ prisma-hyperspectral (accessed on 14 August 2015).

21. HyspIRI. Available online: http:/ /hyspiri.jpl.nasa.gov/ (accessed on 14 August 2015).

22. Tsai, F.; Philpot, W. Derivative analysis of hyperspectral data. Remote Sens. Environ. 1998, 66, 41-51.

23. Gitelson, A.A.; Gao, B.C.; Li, R.R.; Berdnikov, S.; Saprygin, V. Estimation of chlorophyll-a concentration in productive turbid waters using a Hyperspectral Imager for the Coastal Ocean-The Azov Sea case study. Environ. Res. Lett. 2011, 6, doi:10.1088/1748-9326/6/2/024023

24. Matthews, M.W. A current review of empirical procedures of remote sensing in inland and near-coastal transitional waters. Int. J. Remote Sens. 2011, 32, 6855-6899.

25. Odermatt, D.; Gitelson, A.; Brando, V.E.; Schaepman, M. Review of constituent retrieval in optically deep and complex waters from satellite imagery. Remote Sens. Environ. 2012, 118, 116-126.

26. Hestir, E.L.; Brando, V.E.; Bresciani, M.; Giardino, C.; Matta, E.; Villa, P.; Dekker, A.G. Measuring freshwater aquatic ecosystems: The need for a hyperspectral global mapping satellite mission. Remote Sens. Environ. 2015, 167, 181-195.

27. Gordon, H.R.; Wang, M. Retrieval of water-leaving radiance and aerosol optical thickness over the oceans with SeaWiFS: A preliminary algorithm. Appl. Opt. 1994, 33, 443-452.

28. Mobley, C. Light and Water: Radiative Transfer in Natural Waters; Academic Press: San Diego, CA, USA, 1994.

29. Wang, M. Remote sensing of the ocean contributions from ultraviolet to near-infrared using the shortwave infrared bands: Simulations. Appl. Opt. 2007, 46, 1535-1547.

30. IOCCG. Atmospheric Correction for Remotely-Sensed Ocean-Colour Products (Reports of the International Ocean-Colour Coordinating Group, No. 10); Technical Report; Wang M., Ed.; IOCCG Project Office: Dartmouth, NS, Canada, 2010.

31. O’Reilly, J.E.; Maritorena, S.; Mitchell, B.G.; Siegel, D.A.; Carder, K.L.; Garver, S.A.; Kahru, M.; McClain, C. Ocean color chlorophyll algorithms for SeaWiFS. J. Geophys. Res. Oceans (1978-2012) 1998, 103, 24937-24953.

32. Miller, R.L.; McKee, B. Using MODIS Terra $250 \mathrm{~m}$ imagery to map concentrations of total suspended matter in coastal waters. Remote Sens. Environ. 2004, 93, 259-266.

33. Son, S.; Wang, M. Water properties in Chesapeake Bay from MODIS-Aqua measurements. Remote Sens. Environ. 2012, 123, 163-174.

34. Zhang, M.; Tang, J.; Dong, Q.; Song, Q.; Ding, J. Retrieval of total suspended matter concentration in the Yellow and East China Seas from MODIS imagery. Remote Sens. Environ. 2010, 114, 392-403.

35. Lee, Z.; Carder, K.L.; Arnone, R.A. Deriving inherent optical properties from water color: A multiband quasi-analytical algorithm for optically deep waters. Appl. Opt. 2002, 41, 5755-5772.

36. Maritorena, S.; Siegel, D.A.; Peterson, A.R. Optimization of a semianalytical ocean color model for global-scale applications. Appl. Opt. 2002, 41, 2705-2714.

37. Groom, S. Landsat 7 False Colour Image; NERC EO Data Acquisition and Analysis Service: Plymouth, UK, 1999.

38. Chang, G.; Mahoney, K.; Briggs-Whitmire, A.; Kohler, D.; Mobley, C.; Lewis, M.; Moline, M.; Boss, E.; Kim, M.; Philpot, W.; et al. The new age of hyperspectral oceanography. Oceanography 2004, 17, 22-29.

39. Shi, W.; Wang, M. An assessment of the black ocean pixel assumption for MODIS SWIR bands. Remote Sens. Environ. 2009, 113, 1587-1597.

40. Wang, M.; Son, S.; Shi, W. Evaluation of MODIS SWIR and NIR-SWIR atmospheric correction algorithm using SeaBASS data. Remote Sens. Environ. 2009, 113, 635-644.

41. Jamet, C.; Loisel, H.; Kuchinke, C.P.; Ruddick, K.; Zibordi, G.; Feng, H. Comparison of three SeaWiFS atmospheric correction algorithms for turbid waters using AERONET-OC measurements. Remote Sens. Environ. 2011, 115, 1955-1965. 
42. Goyens, C.; Jamet, C.; Schroeder, T. Evaluation of four atmospheric correction algorithms for MODIS-Aqua images over contrasted coastal waters. Remote Sens. Environ. 2013, 131, 63-75.

43. Wang, M.; Shi, W. Estimation of ocean contribution at the MODIS near-infrared wavelengths along the east coast of the U.S.: Two case studies. Geophys. Res. Lett. 2005, 32, L13606.

44. Wang, M.; Shi, W. The NIR-SWIR combined atmospheric correction approach for MODIS ocean color data processing. Opt. Express 2007, 15, 15722-15733.

45. Loisel, H.; Vantrepotte, V.; Jamet, C.; Dat, D.N. Challenges and new advances in ocean color remote sensing of coastal waters. In Topics in Oceanography; Zambianchi, E., Ed.; InTechOpen: Rijeka, Croatia, 2013.

46. Mouw, C.B.; Greb, S.; Aurin, D.; DiGiacomo, P.M.; Lee, Z.; Twardowski, M.; Binding, C.; Hu, C.; Ma, R.; Moore, T.; et al. Aquatic color radiometry remote sensing of coastal and inland waters: Challenges and recommendations for future satellite missions. Remote Sens. Environ. 2015, 160, 15-30.

47. Zibordi, G.; Mélin, F.; Berthon, J.F.; Holben, B.; Slutsker, I.; Giles, D.; D'Alimonte, D.; Vandemark, D.; Feng, H.; Schuster, G.; et al. AERONET-OC: A network for the validation of ocean color primary products. J. Atmos. Oceanic Technol. 2009, 26, 1634-1651.

48. Gordon, H.R. In-orbit calibration strategy for ocean color sensors. Remote Sens. Environ. 1998, 63, $265-278$.

49. Wang, M.; Gordon, H.R. Calibration of ocean color scanners: How much error is acceptable in the near-infrared. Remote Sens. Environ. 2002, 82, 497-504.

50. Franz, B.A.; Bailey, S.W.; Werdell, P.J.; McClain, C.R. Sensor-independent approach to the vicarious calibration of satellite ocean color radiometry. Appl. Opt. 2007, 46, 5068-5082.

51. Lewis, D.; Gould, R.W., Jr.; Ladner, S.D.; Lawson, T.A.; Martinolich, P. Vicarious Calibration of the Hyperspectral Imager for Coastal Oceans (HICO) Using MOBY and AERONET-OC Data; Technical Report, NRL/PP/7330-12-1391; Naval Research Lab, Stennis Detachment, Stennis Space Center: Hancock County, MS, USA, 2012.

52. Clark, D.K.; Gordon, H.R.; Voss, K.J.; Ge, Y.; Broenkow, W.; Trees, C. Validation of atmospheric correction over the ocean. J. Geophys. Res. Atmos. (1984-2012) 1997, 102, 17209-17217.

53. Clark, D.K.; Yarbrough, M.A.; Feinholz, M.; Flora, S.; Broenkow, W.; Kim, Y.S.; Johnson, B.C.; Brown, S.W.; Yuen, M.; Mueller, J.L. MOBY, A Radiometric Buoy for Performance Monitoring and Vicarious Calibration of Satellite Ocean Color Sensors: Measurement and Data Analysis Protocols; Technical Report, NASA/TM-2003-211621/Rev4-Vol. IV; NASA Goddard Space Flight Center: Greenbelt, MD, USA, 2002.

54. Holben, B.N.; Eck, T.F.; Slutsker, I.; Tanre, D.; Buis, J.P.; Setzer, A.; Smirnov, A. AERONET-A federated instrument network and data archive for aerosol characterization. Remote Sens. Environ. 1998, 66, 1-16.

55. AERONET-OC. Available online: http://aeronet.gsfc.nasa.gov/new_web/ocean_color.html (accessed on 14 August 2015).

56. Smirnov, A.; Holben, B.N.; Slutsker, I.; Giles, D.M.; McClain, C.R.; Eck, T.F.; Sakerin, S.M.; Macke, A.; Croot, P.; Zibordi, G.; et al. Maritime aerosol network as a component of aerosol robotic network. J. Geophys. Res. Atmos. (1984-2012) 2009, 114, D06204.

57. Kleidman, R.G.; Smirnov, A.; Levy, R.C.; Mattoo, S.; Tanre, D. Evaluation and wind speed dependence of MODIS aerosol retrievals over open oceans. IEEE Trans. Geosci. Remote Sens. 2012, 50, 429-435.

58. Antoine, D.; Guevel, P.; Deste, J.F.; Becu, G.; Louis, F.; Scott, A.J.; Bardey, P. The “BOUSSOLE” buoy-a new transparent-to-swell taut mooring dedicated to marine optics: Design, tests, and performance at sea. J. Atmos. Oceanic Technol. 2008, 25, 968-989.

59. Clark, D.K.; Feinholz, M.; Yarbrough, M.; Johnson, B.C.; Brown, S.W.; Kim, Y.S.; Barnes, R.A. Overview of the radiometric calibration of MOBY. Proc. SPIE 2002, 4483, 64-76.

60. MOBY. Available online: http://moby.mlml.calstate.edu/MOBY-data (accessed on 14 August 2015).

61. Eplee, R.E., Jr.; Robinson, W.D.; Bailey, S.W.; Clark, D.K.; Werdell, P.J.; Wang, M.; Barnes, R.A.; McClain, C.R. Calibration of SeaWiFS. II: Vicarious techniques. Appl. Opt. 2001, 40, 6701-6718.

62. Wang, M.; Isaacman, A.; Franz, B.A.; McClain, C.R. Ocean color optical property data derived from the Japanese Ocean Color and Temperature Scanner and the French Polarization and Directionality of the Earth's Reflectances: A comparison study. Appl. Opt. 2002, 41, 974-990.

63. CoastWatch. Available online: http://coastwatch.noaa.gov/moby/ (accessed on 14 August 2015).

64. Wang, M.; Shi, W.; Jiang, L.; Liu, X.; Son, S.; Voss, K. Technique for monitoring performance of VIIRS reflective solar bands for ocean color data processing. Opt. Express 2015, 23, 14446-14460. 
65. Zibordi, G.; Melin, F.; Voss, K.; Johnson, B.C.; Franz, B.A.; Kwiatkowska, E.; Huot, J.P.; Wang, M.; Antoine, D. System vicarious calibration for ocean color climate change applications: Requirements for in situ data. Remote Sens. Environ. 2015, 159, 361-369.

66. Argo. Available online: http://www.argo.ucsd.edu (accessed on 14 August 2015).

67. IOCCG. Bio-Optical Sensors on Argo Floats (Reports of the International Ocean-Colour Coordinating Group, No. 11); Technical Report; IOCCG Project Office: Dartmouth, NS, Canada, 2011.

68. Xing, X.; Claustre, H.; Wang, H.; Poteau, A.; D’Ortenzio, F. Seasonal dynamics in colored dissolved organic matter in the Mediterranean Sea: Patterns and drivers. Deep Sea Res. Pt. I: Oceanogr. Res. Pap. 2014, 83, 93-101.

69. Mignot, A.; Claustre, H.; Uitz, J.; Poteau, A.; D'Ortenzio, F.; Xing, X. Understanding the seasonal dynamics of phytoplankton biomass and the deep chlorophyll maximum in oligotrophic environments: A Bio-Argo float investigation. Global Biogeochem. Cycles 2014, 28, 856-876.

70. Xing, X.; Claustre, H.; Uitz, J.; Mignot, A.; Poteau, A.; Wang, H. Seasonal variations of bio-optical properties and their interrelationships observed by Bio-Argo floats in the subpolar North Atlantic. J. Geophys. Res. Oceans 2014, 119, 7372-7388.

71. D’Ortenzio, F.; Lavigne, H.; Besson, F.; Claustre, H.; Coppola, L.; Garcia, N.; Laes-Huon, A.; Reste, S.L.; Malarde, D.; Migon, C.; et al. Observing mixed layer depth, nitrate and chlorophyll concentrations in the northwestern Mediterranean: A combined satellite and NO3 profiling floats experiment. Geophys. Res. Lett. 2014, 41, 6443-6451.

72. Blockstein, L.; Yadid-Pecht, O. Lensless miniature portable fluorometer for measurement of chlorophyll and CDOM in water using fluorescence contact imaging. IEEE Photon. J. 2014, 6, 1-16.

73. Werdell, J. SeaWiFS Bio-Optical Archive and Storage System (SeaBASS). Available online: http:/ / seabass.gsfc.nasa.gov (accessed on 14 August 2015).

74. AVIRIS. Available online: http:/ /aviris.jpl.nasa.gov/ (accessed on 14 August 2015).

75. OCTS. Available online: http:/ / oceancolor.gsfc.nasa.gov/cms/data/octs (accessed on 14 August 2015).

76. SeaWiFS. Available online: http:/ /oceancolor.gsfc.nasa.gov/SeaWiFS/ (accessed on 14 August 2015).

77. Landsat. Available online: http://landsat.gsfc.nasa.gov/ (accessed on 14 August 2015).

78. Hyperion. Available online: http://eo1.usgs.gov/sensors/hyperion (accessed on 14 August 2015).

79. CHRIS. Available online: https://earth.esa.int/web/guest/missions/esa-operational-eo-missions/proba/ instruments/chris (accessed on 14 August 2015).

80. MERIS. Available online: https://earth.esa.int/web/guest/missions/esa-operational-eo-missions/envisat/ instruments/meris (accessed on 14 August 2015).

81. MODIS. Available online: http://modis.gsfc.nasa.gov/ (accessed on 14 August 2015).

82. POLDER. Available online: http://smsc.cnes.fr/PARASOL/ (accessed on 14 August 2015).

83. AVIRIS-NG. Available online: http:/ /avirisng.jpl.nasa.gov/ (accessed on 14 August 2015).

84. GOCI. Available online: http://kosc.kiost.ac/kosc_eng/main/ (accessed on 14 August 2015).

85. Cao, C.; De Luccia, F.J.; Xiong, X.; Wolfe, R.; Weng, F. Early on-orbit performance of the Visible Infrared Imaging Radiometer Suite onboard the Suomi National Polar-Orbiting Partnership (S-NPP) satellites. IEEE Trans. Geosci. Remote Sens. 2014, 52, 1142-1156.

86. PRISM. Available online: http://prism.jpl.nasa.gov/index.html (accessed on 14 August 2015).

87. Imaoka, K.; Kachi, M.; Fujii, H.; Murakami, H.; Hori, M.; Ono, A.; Igarashi, T.; Nakagawa, K.; Oki, T.; Honda, Y.; et al. Global Change Observation Mission (GCOM) for monitoring carbon, water cycles, and climate change. Proc. IEEE 2010, 98, 717-734.

88. OLCI. Available online: https://earth.esa.int/web/guest/missions/esa-future-missions/sentinel-3 (accessed on 14 August 2015).

89. EnMap. Available online: http://www.enmap.org/ (accessed on 14 August 2015).

90. ACE. Available online: http://neptune.gsfc.nasa.gov/osb/index.php?section=241 (accessed on 14 August 2015).

91. PACE. Pre-Aerosol, Clouds, and Ocean Ecosystem (PACE) Mission Science Definition Team Report; Technical Report; NASA Goddard Space Flight Center: Greenbelt, MD, USA, 2012.

92. GOCI-II. Available online: http://www.wmo-sat.info/oscar/instruments/view/674 (accessed on 14 August 2015).

93. GEO-CAPE. Available online: http://geo-cape.larc.nasa.gov/ (accessed on 14 August 2015). 
94. Suomalainen, J.; Anders, N.; Iqbal, S.; Roerink, G.; Franke, J.; Wenting, P.; Hunniger, D.; Bartholomeus, H.; Becker, R.; Kooistra, L. A lightweight hyperspectral mapping system and photogrammetric processing chain for Unmanned Aerial Vehicles. Remote Sens. 2014, 6, 11013-11030.

95. Bissett, W.P.; Arnone, R.A.; Davis, C.O.; Dickey, T.D.; Dye, D.; Kohler, D.D.; Gould, R.W. From meters to milometers: A look at ocean-color scales of variability, spatial coherence, and the need for fine-scale remote sensing in coastal ocean optics. Oceanography 2004, 17, 32-42.

96. Davis, C.O.; Kavanaugh, M.; Letelier, R.; Bissett, W.P.; Kohler, D. Spatial and spectral resolution considerations for imaging coastal waters. Proc. SPIE 2007, 6680, doi:10.1117/12.734288.

97. Chen, J.; Fu, J.; Zhang, M. An atmospheric correction algorithm for Landsat/TM imagery basing on inverse distance spatial interpolation algorithm: A case study in Taihu Lake. IEEE J. Sel. Top. Appl. Earth Observ. 2012, 4, 882-889.

98. Hu, C.; Muller-Karger, F.E.; Andrefouet, S.; Carder, K.L. Atmospheric correction and cross-calibration of LANDSAT-7/ETM+ imagery over aquatic environments: A multiplatform approach using SeaWiFS/ MODIS. Remote Sens. Environ. 2001, 78, 99-107.

99. Vanhellemont, Q.; Ruddick, K. Turbid wakes associated with offshore wind turbines observed with Landsat 8. Remote Sens. Environ. 2014, 145, 105-115.

100. Guanter, L.; Segl, K.; Kaufmann, H. Simulation of optical remote-sensing scenes with application to the EnMAP hyperspectral mission. IEEE Trans. Geosci. Remote Sens. 2009, 47, 2340-2351.

101. Hu, C.; Feng, L.; Lee, Z.; Davis, C.O.; Mannino, A.; McClain, C.R.; Franz, B.A. Dynamic range and sensitivity requirements of satellite ocean color sensors: Learning from the past. Appl. Opt. 2012, $51,6045-6062$.

102. Moses, W.J.; Gitelson, A.A.; Berdnikov, S.; Bowles, J.H.; Povazhnyi, V.; Saprygin, V.; Wagner, E.J.; Patterson, K.W. HICO-based NIR-red models for estimating chlorophyll-concentration in productive coastal waters. IEEE Geosci. Remote Sens. Lett. 2014, 11, 1111-1115.

103. Mallinis, G.; Galidaki, G.; Gitas, I. A comparative analysis of EO-1 Hyperion, Quickbird and Landsat TM imagery for fuel type mapping of a typical Mediterranean landscape. Remote Sens. 2014, 6, 1684-1704.

104. Gao, B.C.; Li, R.R. Removal of thin cirrus scattering effects for remote sensing of ocean color from space. IEEE Geosci. Remote Sens. Lett. 2012, 9, 972-976.

105. Moses, W.J.; Gitelson, A.A.; Perk, R.L.; Gurlin, D.; Rundquist, D.C.; Leavitt, B.C.; Barrow, T.M.; Brakhage, P. Estimation of chlorophyll-a concentration in turbid productive waters using airborne hyperspectral data. Water Res. 2012, 46, 993-1004.

106. Ryan, J.P.; Davis, C.O.; Tufillaro, N.B.; Kudela, R.M.; Gao, B.C. Application of the Hyperspectral Imager for the Coastal Ocean to phytoplankton ecology studies in Monterey Bay, CA, USA. Remote Sens. 2014, 6, 1007-1025.

107. Braga, F.; Giardino, C.; Bassani, C.; Matta, E.; Candiani, G.; Strömbeck, N.; Adamo, M.; Bresciani, M. Assessing water quality in the northern Adriatic Sea from HICO data. Remote Sens. Lett. 2013, 4, 1028-1037.

108. Cho, H.J.; Ogashawara, I.; Mishra, D.; White, J.; Kamerosky, A.; Morris, L.; Clarke, C.; Simpson, A.; Banisakher, D. Evaluating Hyperspectral Imager for the Coastal Ocean (HICO) data for seagrass mapping in Indian River Lagoon, FL. GISci. Remote Sens. 2014, 51, 120-138.

109. Gao, B. C.; Montes, M. J.; Ahmad, Z.; Davis, C. O. Atmospheric correction algorithm for hyperspectral remote sensing of ocean color from space. Appl. Opt. 2000, 39, 887-896.

110. Ruddick, K.G.; Ovidio, F.; Rijkeboer, M. Atmospheric correction of SeaWiFS imagery for turbid coastal and inland waters. Appl. Opt. 2000, 39, 897-912.

111. Siegel, D.A.; Wang, M.; Maritorena, S.; Robinson, W. Atmospheric correction of satellite ocean color imagery: The black pixel assumption. Appl. Opt. 2000, 39, 3582-3591.

112. Patterson, K.W.; Lamela, G. Influence of aerosol estimation on coastal water products retrieved from HICO images. Proc. SPIE 2011, 8030, 25-28.

113. Bassani, C.; Manzo, C.; Braga, F.; Bresciani, M.; Giardino, C.; Alberotanza, L. Impact of the aerosol type on HICO atmospheric correction in coastal waters. Atmos. Meas. Tech. Discuss. 2014, 7, 5147-5172.

114. Devred, E.; Turpie, K.R.; Moses, W.; Klemas, V.V.; Moisan, T.; Babin, M.; Toro-Farmer, G.; Forget, M.; Jo, Y.H. Future retrievals of water column bio-optical properties using the hyperspectral infrared imager (HyspIRI). Remote Sens. 2013, 5, 6812-6837. 
115. Lucke, R. L.; Corson, M.; McGlothlin, N. R.; Butcher, S. D.; Wood, D. L.; Korwan, D. R.; Li, R. R.; Snyder, W. A.; Davis, C. O.; Chen, D. T. Hyperspectral imager for the coastal ocean: Instrument description and first images. Appl. Opt. 2011, 50, 1501-1516.

116. Cho, S.; Ahn, Y.H.; Ryu, J.H.; Kang, G.; Youn, H. Development of geostationary ocean color imager (GOCI). Korean J. Remote Sens. 2010, 26, 157-165.

117. Choi, J.K.; Park, Y.J.; Ahn, J.H.; Lim, H.S.; Eom, J.; Ryu, J.H. GOCI, the world's first geostationary ocean color observation satellite, for the monitoring of temporal variability in coastal water turbidity. J. Geophys. Res. Oceans (1984-2012) 2012, 117, C09004.

118. Ryu, J.H.; Choi, J.K.; Eom, J.; Ahn, J.H. Temporal variation in Korean coastal waters using Geostationary Ocean Color Imager. J. Coast. Res. 2011, 64, 1731-1735.

119. Wang, M.; Ahn, J.H.; Jiang, L.; Shi, W.; Son, S.; Park, Y.J.; Ryu, J.H. Ocean color products from the Korean Geostationary Ocean Color Imager (GOCI). Opt. Express 2013, 21, 3835-3849.

120. Kahn, R.A.; Gaitley, B.J.; Martonchik, J.V.; Diner, D.J.; Crean, K.A.; Holben, B. Multiangle Imaging SpectroRadiometer (MISR) global aerosol optical depth validation based on 2 years of coincident Aerosol Robotic Network (AERONET) observations. J. Geophys. Res. Atmos. (1984-2012) 2005, 110, D10S04.

121. Kahn, R.A.; Garay, M.J.; Nelson, D.L.; Yau, K.K.; Bull, M.A.; Gaitley, B.J.; Martonchik, J.V.; Levy, R.C. Satellite-derived aerosol optical depth over dark water from MISR and MODIS: Comparisons with AERONET and implications for climatological studies. J. Geophys. Res. Atmos. (1984-2012) 2007, 112, D18205.

122. Kahn, R.A.; Nelson, D.L.; Garay, M.J.; Levy, R.C.; Bull, M.A.; Diner, D.J.; Martonchik, J.V.; Paradise, S.R.; Hansen, E.G.; Remer, L.A. MISR aerosol product attributes and statistical comparisons with MODIS. IEEE Trans. Geosci. Remote Sens. 2009, 47, 4095-4114.

123. Kahn, R.A.; Gaitley, B.J.; Garay, M.J.; Diner, D.J.; Eck, T.F.; Smirnov, A.; Holben, B.N. Multiangle Imaging SpectroRadiometer global aerosol product assessment by comparison with the Aerosol Robotic Network. J. Geophys. Res. Atmos. (1984-2012) 2010, 115, D23209.

124. Bevan, S.L.; North, P.R.; Los, S.O.; Grey, W.M. A global dataset of atmospheric aerosol optical depth and surface reflectance from AATSR. Remote Sens. Environ. 2012, 116, 199-210.

125. Harmel, T.; Chami, M. Influence of polarimetric satellite data measured in the visible region on aerosol detection and on the performance of atmospheric correction procedure over open ocean waters. Opt. Express 2011, 19, 20960-20983.

126. He, X.; Pan, D.; Bai, Y.; Wang, D.; Hao, Z. A new simple concept for ocean colour remote sensing using parallel polarisation radiance. Sci. Rep. 2014, 4, doi:10.1038/srep03748.

127. Meister, G.; McClain, C.R.; Ahmad, Z.; Bailey, S.W.; Barnes, R.A.; Brown, S.; Eplee, R.E.; Franz, B.; Holmes, A.; Monosmith, W.B.; et al. Requirements for an Advanced Ocean Radiometer; Technical Report; NASA Goddard Space Flight Center: Greenbelt, MD, USA, 2011.

128. IOCCG. Mission Requirements for Future Ocean-Colour Sensors (Reports of the International Ocean-Colour Coordinating Group, No. 13); Technical Report; IOCCG Project Office: Dartmouth, Canada, 2012.

129. Iwasaki, A.; Ohgi, N.; Tanii, J.; Kawashima, T.; Inada, H. Hyperspectral Imager Suite (HISUI)-Japanese hyper-multi spectral radiometer. In Proceedings of the IEEE Geoscience and Remote Sensing Symposium, Vancouver, BC, Canada, 24-29 July 2011; pp. 1025-1028.

130. Galeazzi, C.; Sacchetti, A.; Cisbani, A.; Babini, G. The PRISMA program. In Proceedings of the IEEE Geoscience and Remote Sensing Symposium, Boston, MA, USA, 7-11 July 2008; Volume 4, pp. 105-108.

131. McClain, C.R. The Ocean Radiometer for Carbon Assessment (ORCA); Technical Report; NASA Goddard Space Flight Center: Greenbelt, MD, USA, 2010.

132. Amin, R.; Lewis, D.; Gould, R.W.; Hou, W.; Lawson, A.; Ondrusek, M.; Arnone, R. Assessing the application of cloud-shadow atmospheric correction algorithm on HICO. IEEE Trans. Geosci. Remote Sens. 2014, $52,2646-2653$.

133. Bracchini, L.; Tognazzi, A.; Dattilo, A.M.; Decembrini, F.; Rossi, C.; Loiselle, S.A. Sensitivity analysis of CDOM spectral slope in artificial and natural samples: An application in the central eastern Mediterranean Basin. Aquat. Sci. 2010, 72, 485-498.

134. Helms, J.R.; Stubbins, A.; Ritchie, J.D.; Minor, E.C.; Kieber, D.J.; Mopper, K. Absorption spectral slopes and slope ratios as indicators of molecular weight, source, and photobleaching of chromophoric dissolved organic matter. Limnol. Oceanogr. 2008, 53, 955-969. 
135. He, X.; Bai, Y.; Pan, D.; Tang, J.; Wang, D. Atmospheric correction of satellite ocean color imagery using the ultraviolet wavelength for highly turbid waters. Opt. Express 2012, 20, 20754-20770.

136. Kudela, R.M.; Palacios, S.L.; Austerberry, D.C.; Accorsi, E.K.; Guild, L.S.; Torres-Perez, J. Application of hyperspectral remote sensing to cyanobacterial blooms in inland waters. Remote Sens. Environ. 2015, 167, 196-205.

137. Mouroulis, P.; Gorp, B.V.; Green, R.O.; Dierssen, H.; Wilson, D.W.; Eastwood, M.; Boardman, J.; Gao, B.C.; Cohen, D.; Franklin, B.; et al. Portable Remote Imaging Spectrometer coastal ocean sensor: Design, characteristics, and first flight results. Appl. Opt. 2014, 53, 1363-1380.

138. Palacios, S.L.; Kudela, R.M.; Guild, L.S.; Negrey, K.H.; Torres-Perez, J.; Broughton, J. Remote sensing of phytoplankton functional types in the coastal ocean from the HyspIRI Preparatory Flight Campaign. Remote Sens. Environ. 2015, 167, 269-280.

139. Dierssen, H.M.; Chlus, A.; Russell, B. Hyperspectral discrimination of floating mats of seagrass wrack and the macroalgae Sargassum in coastal waters of Greater Florida Bay using airborne remote sensing. Remote Sens. Environ. 2015, 167, 247-258.

140. Hochberg, E.J.; Roberts, D.A.; Dennison, P.E.; Hulley, G.C. Special issue on the Hyperspectral Infrared Imager (HyspIRI): Emerging science in terrestrial and aquatic ecology, radiation balance and hazards. Remote Sens. Environ. 2015, 167, 1-5.

141. Turpie, K.R.; Klemas, V.V.; Byrd, K.; Kelly, M.; Jo, Y.H. Prospective HyspIRI global observations of tidal wetlands. Remote Sens. Environ. 2015, 167, 206-217.

142. Bell, T.W.; Cavanaugh, K.C.; Siegel, D.A. Remote monitoring of giant kelp biomass and physiological condition: An evaluation of the potential for the Hyperspectral Infrared Imager (HyspIRI) mission. Remote Sens. Environ. 2015, 167, 218-228.

143. Hu, C.; Feng, L.; Hardy, R.F.; Hochberg, E.J. Spectral and spatial requirements of remote measurements of pelagic Sargassum macroalgae. Remote Sens. Environ. 2015, 167, 229-246.

144. Lorenzoni, L.; Toro-Farmer, G.; Varela, R.; Guzman, L.; Rojas, J.; Montes, E.; Muller-Karger, F. Characterization of phytoplankton variability in the Cariaco Basin using spectral absorption, taxonomic and pigment data. Remote Sens. Environ. 2015, 167, 259-268.

145. Thompson, D.R.; Gao, B.C.; Green, R.O.; Roberts, D.A.; Dennison, P.E.; Lundeen, S.R. Atmospheric correction for global mapping spectroscopy: ATREM advances for the HyspIRI preparatory campaign. Remote Sens. Environ. 2015, 167, 64-77.

146. Kutser, T. Quantitative detection of chlorophyll in cyanobacterial blooms by satellite remote sensing. Limnol. Oceanogr. 2004, 49, 2179-2189.

147. Cavanaugh, K.C.; Siegel, D.A.; Raimondi, P.T.; Alberto, F. Patch definition in metapopulation analysis: A graph theory approach to solve the mega-patch problem. Ecology 2014, 95, 316-328.

148. IOCCG. Phytoplankton Functional Types from Space; Technical Report of the International Ocean-Colour Coordinating Group, No. 15; Sathyendranath, S., Ed.; IOCCG Project Office: Dartmouth, NS, Canada, 2014.

149. Gao, B.C.; Heidebrecht, K.B.; Goetz, A.F.H. Atmosphere Removal Program (ATREM) Version 2.0 Users Guide; Technical Report; Center for the Study of Earth from Space/CIRES, University of Colorado: Boulder, CO, USA, 1996.

150. Fishman, J.; Iraci, L.T.; Al-Saadi, J.; Chance, K.; Chavez, F.; Chin, M.; Coble, P.; Davis, C.; DiGiacomo, P.M.; Eldering, A.; et al. The United States' next generation of atmospheric composition and coastal ecosystem measurements: NASA's geostationary coastal and air pollution events (GEO-CAPE) missions. Bull. Am. Meteor. Soc. 2012, 93, 1547-1566.

151. Wang, M.; Shi, W.; Jiang, L. Atmospheric correction using near-infrared bands for satellite ocean color data processing in the turbid western Pacific region. Opt. Express 2012, 20, 741-753.

152. Mobley, C.; Boss, E.; Roesler, C. Ocean Optics Web Book. Available online: http:/ / www.oceanopticsbook.info (accessed on 14 August 2015).

153. Gordon, H.R. Atmospheric correction of ocean color imagery in the Earth Observing System era. J. Geophys. Res. Atmos. (1984-2012) 1997, 102, 17081-17106.

154. Griffin, M.K.; Burke, H.H.K. Compensation of hyperspectral data for atmospheric effects. Linc. Lab. J. 2003, $14,29-54$. 
155. Gordon, H.R.; Brown, J.W.; Evans, R.H. Exact Rayleigh scattering calculations for use with the Nimbus-7 Coastal Zone Color Scanner. Appl. Opt. 1988, 27, 862-871.

156. Gordon, H.R.; Wang, M. Surface roughness considerations for atmospheric correction of ocean color sensors. 1: The Rayleigh scattering component. Appl. Opt. 1992, 31, 4247-4260.

157. Wang, M. The Rayleigh lookup tables for the SeaWiFS data processing: Accounting for the effects of ocean surface roughness. Int. J. Remote Sens. 2002, 23, 2693-2702.

158. Wang, M. A refinement for the Rayleigh radiance computation with variation of the atmospheric pressure. Int. J. Remote Sens. 2005, 26, 5651-5663.

159. Ahmad, Z.; Franz, B.A.; McClain, C.R.; Kwiatkowska, E.J.; Werdell, J.; Shettle, E.P.; Holben, B.N. New aerosol models for the retrieval of aerosol optical thickness and normalized water-leaving radiances from the SeaWiFS and MODIS sensors over coastal regions and open oceans. Appl. Opt. 2010, 49, 5545-5560.

160. Shettle, E.P.; Fenn, R.W. Models for the Aerosols of the Lower Atmosphere and the Effects of Humidity Variations on Their Optical Properties; Technical Report; AFGL-TR-79-0214; Air Force Geophysics Lab: Hanscom AFB, MA, USA, 1979.

161. Moulin, C.; Gordon, H.R.; Banzon, V.F.; Evans, R.H. Assessment of Saharan dust absorption in the visible from SeaWiFS imagery. J. Geophys. Res. Atmos. (1984-2012) 2001, 106, 18239-18249.

162. Dubovik, O.; Sinyuk, A.; Lapyonok, T.; Holben, B.N.; Mishchenko, M.; Yang, P.; Eck, T.; Volten, H.; Munoz, O.; Veihelmann, B.; et al. Application of spheroid models to account for aerosol particle nonsphericity in remote sensing of desert dust. J. Geophys. Res. Atmos. (1984-2012) 2006, 111, 2156-2202.

163. Steinmetz, F.; Deschamps, P.Y.; Ramon, D. Atmospheric correction in presence of sun glint: Application to MERIS. Opt. Express 2011, 19, 9783-9800.

164. Chomko, R.M.; Gordon, H.R. Atmospheric correction of ocean color imagery: Use of the Junge power-law aerosol size distribution with variable refractive index to handle aerosol absorption. Appl. Opt. 1998, $37,5560-5572$.

165. Chomko, R.M.; Gordon, H.R.; Maritorena, S.; Siegel, D.A. Simultaneous retrieval of oceanic and atmospheric parameters for ocean color imagery by spectral optimization: A validation. Remote Sens. Environ. 2003, 84, 208-220.

166. Brajard, J.; Jamet, C.; Moulin, C.; Thiria, S. Use of a neuro-variational inversion for retrieving oceanic and atmospheric constituents from satellite ocean colour sensor: Application to absorbing aerosols. Neural. Netw. 2006, 19, 178-185.

167. Brajard, J.; Moulin, C.; Thiria, S. Atmospheric correction of SeaWiFS ocean color imagery in the presence of absorbing aerosols off the Indian coast using a neuro-variational methods. Geophys. Res. Lett. 2008, 35, 1944-8007.

168. Frouin, R.; Schwindling, M.; Deschamps, P.Y. Spectral reflectance of sea foam in the visible and near-infrared: In situ measurements and remote sensing implications. J. Geophys. Res. Oceans (1978-2012) 1996, 101, 14361-14371.

169. Koepke, P. Effective reflectance of oceanic whitecaps. Appl. Opt. 1984, 23, 1816-1824.

170. Moore, K.D.; Voss, K.J.; Gordon, H.R. Spectral reflectance of whitecaps: Their contribution to water-leaving radiances. J. Geophys. Res. Oceans (1978-2012) 2000, 105, 6493-6499.

171. Gordon, H.R.; Wang, M. Influence of oceanic whitecaps on atmospheric correction of ocean-color sensor. Appl. Opt. 1994, 33, 7754-7763.

172. Cox, C.; Munk, W. Measurement of the roughness of the sea surface from photographs of the sun's glitter. J. Opt. Soc. Am 1954, 44, 838-850.

173. NCEP. Available online: http://oceancolor.gsfc.nasa.gov/cms/ancillary (accessed on 14 August 2015).

174. Fore, A.G.; Yueh, S.H.; Tang, W.; Hayashi, A.K.; Lagerloef, G.S. Aquarius wind speed products: Algorithms and validation. IEEE Trans. Geosci. Remote Sens. 2014, 52, 2920-2927.

175. Wang, M.; Bailey, S. Correction of the sun glint contamination on the SeaWiFS ocean and atmosphere products. Appl. Opt. 2001, 40, 4790-4798.

176. Zhang, H.; Wang, M. Evaluation of sun glint models using MODIS measurements. J. Quant. Spectrosc. Radiat. Transf. 2010, 111, 492-506.

177. Garaba, S.P.; Zielinski, O. Methods in reducing surface reflected glint for shipborne above-water remote sensing. J. Eur. Opt. Soc. 2013, 8, doi:10.2971/jeos.2013.13058. 
178. Van Mol, B.; Ruddick, K. The Compact High Resolution Imaging Spectrometer (CHRIS): the future of hyperspectral satellite sensors. Imagery of Oostende coastal and inland waters. In Proceedings of the Airborne Imaging Spectroscopy workshop, Bruges, Belgium, 8 October 2004.

179. Montes, M.J.; Gao, B.; Davis, C.O. Hyperspectral remote sensing of ocean colour: A comparison of Hyperion and AVIRIS. In Proceedings of the 13th JPL Airborne Earth Science Workshop, Pasadena, CA, USA, 31 March-2 April 2004; pp. 175-180.

180. Harmel, T.; Chami, M. Estimation of the sunglint radiance field from optical satellite imagery over open ocean: Multidirectional approach and polarization aspects. J. Geophys. Res. Oceans 2013, 118, 76-90.

181. Hooker, S.B.; Lazin, G.; Zibordi, G.; McLean, S. An evaluation of above-and in-water methods for determining water-leaving radiances. J. Atmos. Oceanic Technol. 2002, 19, 486-514.

182. Shanmugam, P. CAAS: An atmospheric correction algorithm for the remote sensing of complex waters. Ann. Geophys. 2012, 30, 203-220.

183. Gao, B.C.; Kaufman, Y.J. Water vapor retrievals using Moderate Resolution Imaging Spectroradiometer (MODIS) near-infrared channels. J. Geophys. Res. Atmos. (1984-2012) 2003, 108, doi:10.1029/2002JD003023.

184. Kaufman, Y.J.; Martins, J.V.; Remer, L.A.; Schoeberl, M.R.; Yamasoe, M.A. Satellite retrieval of aerosol absorption over the oceans using sunglint. Geophys. Res. Lett. 2002, 29, doi:10.1029/2002GL015403.

185. Hagolle, O.; Nicolas, J.M.; Fougnie, B.; Cabot, F.; Henry, P. Absolute calibration of VEGETATION derived from an interband method based on the sun glint over ocean. IEEE Trans. Geosci. Remote Sens. 2004, $42,1472-1481$.

186. Robinson, W.D.; Franz, B.A.; Patt, F.S.; Bailey, S.W.; Werdell, P.J. Masks and flags updates, SeaWiFS Postlaunch Technical Report Series, Vol. 22; Technical Report, NASA/TM-2003-206892; Hooker, S.B., Firestone, E.R., Eds.; NASA Goddard Space Flight Center: Greenbelt, MD, USA, 2003.

187. Wang, M.; Shi, W. Cloud masking for ocean color data processing in the coastal regions. IEEE Trans. Geosci. Remote Sens. 2006, 44, 3196-3205.

188. Zhao, G.; Girolamo, L.D.; Dey, S.; Jones, A.L.; Bull, M. Examination of direct cumulus contamination on MISR-retrieved aerosol optical depth and Angstrom coefficient over ocean. Geophys. Res. Lett. 2009, 36, L13811.

189. Nordkvist, K.; Loisel, H.; Gaurier, L.D. Cloud masking of SeaWiFS images over coastal waters using spectral variability. Opt. Express 2009, 17, 12246-12258.

190. Amato, U.; Antoniadis, A.; Cuomo, V.; Cutillo, L.; Franzese, M.; Murino, L.; Serio, C. Statistical cloud detection from SEVIRI multispectral images. Remote Sens. Environ. 2008, 112, 750-766.

191. Lee, Y.; Wahba, G.; Ackerman, S.A. Cloud classification of satellite radiance data by multicategory support vector machines. J. Atmos. Oceanic Technol. 2004, 21, 159-169.

192. Tian, B.; Shaikh, M.A.; Azimi-Sadjadi, M.R.; Haar, T.H.V.; Reinke, D.L. A study of cloud classification with neural networks using spectral and textural features. IEEE Trans. Neural Netw. 1999, 10, 138-151.

193. Gomez-Chova, L.; Camps-Valls, G.; Calpe-Maravilla, J.; Guanter, L.; Moreno, J. Cloud-screening algorithm for ENVISAT/MERIS multispectral images. IEEE Trans. Geosci. Remote Sens. 2007, 45, 4105-4118.

194. King, N.; Vaughan, G. Vertical profile retrievals of marine stratocumulus from passive remote sensing: An assessment of information content and the potential for improved retrievals from hyperspectral measurements. Presented at the EGU General Assembly Conference Abstracts, Vienna, Austria, 22-27 April 2012; pp. 5454.

195. Purdom, J.F.W. Geostationary hyperspectral imaging and sounding: A revolutionary breakthrough in satellite derived cloud motion vectors. In Proceedings of the Chairperson of Session VI: Research Methods and Applications; 7th International Winds Workshop, Helsinki, Finland, 14-17 June 2004.

196. Gomez-Chova, L.; Camps-Valls, G.; Amorós-López, J.; Calpe, J.; Guanter, L.; Alonso, L.; Fortea, J.C.; Moreno, J. Cloud Probability Mask for PROBA/CHRIS Hyperspectral Images. In Proceedings of the IV CHRIS/Proba Workshop, Frascati, Italy, 19-21 September 2006.

197. Anderson, G.P.; Pukall, B.; Allred, C.L.; Jeong, L.S.; Hoke, M.A.H.M.; Chetwynd, J.H.; Adler-Golden, S.M.; Berk, A.; Bernstein, L.S.; et al. FLAASH and MODTRAN4: state-of-the-art atmospheric correction for hyperspectral data. In Proceedings of the IEEE Aerospace Conference, Aspen, CO, USA, 7 March 1999; pp. 177-181.

198. Richter, R.; Schlapfer, D. Atmospheric/Topographic Correction for Airborne Imagery: ATCOR-4 User Guide; Technical Report; DLR: Wessling, Germany, 2008. 
199. Arai, K. Adjacency effect of layered clouds estimated with Monte Carlo simulations. Adv. Space Res. 2002, $29,1807-1812$.

200. Burazerovic, D.; Heylen, R.; Geens, B.; Sterckx, S.; Scheunders, P. Detecting the adjacency effect in hyperspectral imagery with spectral unmixing techniques. IEEE J. Sel. Topics Appl. Earth Observ. 2013, 6, 1070-1078.

201. Santer, R.; Sterckx, S. SIMEC-ICOL-ODESA processing MERIS (ISECA-A2); Technical Report for ADRINORD: Lille, France; VITO: Mol, Belgium, 2013.

202. Kratzer, S.; Vinterhav, C. Improvement of MERIS level 2 products in Baltic Sea coastal areas by applying the Improved Contrast between Ocean and Land processor (ICOL)-data analysis and validation. Oceanologia 2010, 52, 211-236.

203. Sterckx, S.; Knaeps, S.; Kratzer, S.; Ruddick, K. SIMilarity Environment Correction (SIMEC) applied to MERIS data over inland and coastal waters. Remote Sens. Environ. 2014, 157, 96-110.

204. Sterckx, S.; Knaeps, E.; Ruddick, K. Detection and correction of adjacency effects in hyperspectral airborne data of coastal and inland waters: The use of the near infrared similarity spectrum. Int. J. Remote Sens. 2011, 32, 6479-6505.

205. Stumpf, R.P.; Arnone, R.A.; Gould, R.W.; Martinolich, P.M.; Ransibrahmanakul, V. A Partially Coupled Ocean-Atmosphere Model for Retrieval of Water-Leaving Radiance from SeaWiFS in Coastal Waters; Technical Report; NASA/TM-2003-206892; Hooker, S B., Firestone, E.R., Eds.; NASA Goddard Space Flight Center: Greenbelt, MD, USA, 2003.

206. Bailey, S.W.; Franz, B.A.; Werdell, P.J. Estimation of near-infrared water-leaving reflectance for satellite ocean color data processing. Opt. Express 2010, 18, 7521-7527.

207. Ruddick, K.; Cauwer, V.D.; Park, Y.J.; Moore, G. Seaborne measurements of near infrared water-leaving reflectance: The similarity spectrum for turbid waters. Limnol. Oceanogr. 2006, 51, 1167-1179.

208. Jiang, L.; Wang, M. Improved near-infrared ocean reflectance correction algorithm for satellite ocean color data processing. Opt. Express 2014, 22, 21657-21678.

209. Li, R.R.; Kaufman, Y.J.; Gao, B.C.; Davis, C.O. Remote sensing of suspended sediments and shallow coastal waters. IEEE Trans. Geosci. Remote Sens. 2003, 41, 559-566.

210. Shi, W.; Wang, M. Characterization of global ocean turbidity from Moderate Resolution Imaging Spectroradiometer ocean color observations. J. Geophys. Res. Oceans (1978-2012) 2010, 115, C11022.

211. Son, S.; Wang, M.; Harding, L.W., Jr. Satellite-measured net primary production in the Chesapeake Bay. Remote Sens. Environ. 2014, 144, 109-119.

212. Wang, M.; Nim, C.J.; Son, S.; Shi, W. Characterization of turbidity in Florida's Lake Okeechobee and Caloosahatchee and St. Lucie estuaries using MODIS-Aqua measurements. Water Res. 2012, 46, 5410-5422.

213. Wang, M.; Son, S.; Zhang, Y.; Shi, W. Remote sensing of water optical property for China's inland Lake Taihu using the SWIR atmospheric correction with 1640 and $2130 \mathrm{~nm}$ bands. IEEE J. Sel. Topics Appl. Earth Observ. 2013, 6, 2505-2516.

214. Wang, M.; Tang, J.; Shi, W. MODIS-derived ocean color products along the China east coastal region. Geophys. Res. Lett. 2007, 34, L06611.

215. Shi, W.; Wang, M. Ocean reflectance spectra at the red, near-infrared, and shortwave infrared from highly turbid waters: A study in the Bohai Sea, Yellow Sea, and East China Sea. Limnol. Oceanogr. 2014, $59,427-444$.

216. Shi, W.; Wang, M. Decadal changes of water properties in the Aral Sea observed by MODIS-Aqua. J. Geophys. Res. Oceans 2015, 120, 4687-4708.

217. Wang, M.; Shi, W. Sensor noise effects of the SWIR bands on MODIS-derived ocean color products. IEEE Trans. Geosci. Remote Sens. 2012, 50, 3280-3292.

218. Chen, J.; Cui, T.; Lin, C. An improved SWIR atmospheric correction model: A cross-calibration-based model. IEEE Trans. Geosci. Remote Sens. 2014, 52, 3959-3967.

219. Singh, R.K.; Shanmugam, P. A novel method for estimation of aerosol radiance and its extrapolation in the atmospheric correction of satellite data over optically complex oceanic waters. Remote Sens. Environ. 2014, $142,188-206$.

220. Oo, M.; Vargas, M.; Gilerson, A.; Gross, B.; Moshary, F.; Ahmed, S. Improving atmospheric correction for highly productive coastal waters using the short wave infrared retrieval algorithm with water-leaving reflectance constraints at $412 \mathrm{~nm}$. Appl. Opt. 2008, 47, 3846-3859. 
221. Shi, W.; Wang, M. Detection of turbid waters and absorbing aerosols for the MODIS ocean color data processing. Remote Sens. Environ. 2007, 110, 149-161.

222. Banzon, V.F.; Gordon, H.R.; Kuchinke, C.P.; Antoine, D.; Voss, K.J.; Evans, R.H. Validation of a SeaWiFS dust-correction methodology in the Mediterranean Sea: Identification of an algorithm-switching criterion. Remote Sens. Environ. 2009, 113, 2689-2700.

223. Kuchinke, C.P.; Gordon, H.R.; Harding, L.W., Jr.; Voss, K.J. Spectral optimization for constituent retrieval in Case 2 waters II: Validation study in the Chesapeake Bay. Remote Sens. Environ. 2009, 113, 610-621.

224. Kuchinke, C.P.; Gordon, H.R.; Franz, B.A. Spectral optimization for constituent retrieval in Case 2 waters I: Implementation and performance. Remote Sens. Environ. 2009, 113, 571-587.

225. Doerffer, R.; Helmut, S. Neural network for retrieval of concentrations of water constituents with the possibility of detecting exceptional out of scope spectra. In Proceedings of the IEEE Geoscience and Remote Sensing Symposium, Honolulu, HI, USA, 24-28 July 2000; pp. 714-717.

226. Schiller, H.; Doerffer, R. Neural network for emulation of an inverse model operational derivation of Case II water properties from MERIS data. Int. J. Remote Sens. 1999, 20, 1735-1746.

227. Doerffer, R.; Schiller, H. MERIS Regional Coastal and Lake Case 2 Water Project Atmospheric Correction; Technical Report; Algorithm Theoretical Basis Document (ATBD); GKSS Research Center: Geesthacht, Germany, 2008.

228. Vilas, L.G.; Spyrakos, E.; Palenzuela, J.M.T. Neural network estimation of chlorophyll a from MERIS full resolution data for the coastal waters of Galician rias (NW Spain). Remote Sens. Environ. 2011, 115, 524-535.

229. Brajard, J.; Jamet, C.; Moulin, C.; Thiria, S. Validation of a neuro-variational inversion of ocean colour images. Adv. Space Res. 2006, 38, 2169-2175.

230. Jamet, C.; Thiria, S.; Moulin, C.; Crépon, M. Use of a neurovariational inversion for retrieving oceanic and atmospheric constituents from ocean color imagery: A feasibility study. J. Atmos. Oceanic Technol. 2005, $22,460-475$.

231. Brajard, J.; Santer, R.; Crépon, M.; Thiria, S. Atmospheric correction of MERIS data for case-2 waters using a neuro-variational inversion. Remote Sens. Environ. 2012, 126, 51-61.

232. Kokhanovsky, A.A.; Deuzé, J.L.; Diner, D.J.; Dubovik, O.; Ducos, F.; Emde, C.; Garay, M.J.; Grainger, R.G.; Heckel, A.; Herman, M.; et al. The inter-comparison of major satellite aerosol retrieval algorithms using simulated intensity and polarization characteristics of reflected light. Atmos. Meas. Tech. 2010, 3, 909-932.

233. Omar, A.H.; Winker, D.M.; Kittaka, C.; Vaughan, M.A.; Liu, Z.; Hu, Y.; Hostetler, C.A.; Kittaka, C.; Rogers, R.R.; Kuehn, R.E.; et al. The CALIPSO automated aerosol classification and lidar ratio selection algorithm. J. Atmos. Oceanic Technol. 2009, 26, 1994-2014.

234. Winker, D.M.; Pelon, J.; Coakley, J.A.; Ackerman, S.A.; Charlson, R.J.; Colarco, P.R.; Flamant, P.; Fu, Q.; Hoff, R.M.; Kittaka, C.; et al. The CALIPSO Mission: A global 3D view of aerosols and clouds. Bull. Amer. Meteor. Soc. 2010, 91, 1211-1229.

235. Sun, G.; Niu, Z.; Gao, S.; Huang, W.; Wang, L.; Li, W.; Feng, M. 32-channel hyperspectral waveform LiDAR instrument to monitor vegetation: Design and initial performance trials. Proc. SPIE 2014, 9263, doi:10.1117/12.2066788.

236. Fukushima, H.; Toratani, M.; Murakami, H.; Deschamps, P.Y.; Frouin, R.; Tanaka, A. Evaluation of ADEOS-II GLI ocean color atmospheric correction using SIMBADA handheld radiometer data. J. Oceanogr. 2007, 63, 533-543.

237. Toratani, M.; Fukushima, H.; Murakami, H.; Tanaka, A. Atmospheric correction scheme for GLI with absorptive aerosol correction. J. Oceanogr. 2007, 63, 525-532.

238. Moore, G.F.; Aiken, J.; Lavender, S.J. The atmospheric correction of water colour and the quantitative retrieval of suspended particulate matter in Case II waters: Application to MERIS. Int. J. Remote Sens. 1999, 20, 1713-1733.

239. Mao, Z.; Chen, J.; Hao, Z.; Pan, D.; Tao, B.; Zhu, Q. A new approach to estimate the aerosol scattering ratios for the atmospheric correction of satellite remote sensing data in coastal regions. Remote Sens. Environ. 2013, 132, 186-194.

240. Ali, K.A.; Ortiz, J.D. Multivariate approach for chlorophyll-a and suspended matter retrievals in Case II type waters using hyperspectral data. Hydrolog. Sci. J. 2014.

241. Lee, Z.; Shang, S.; Hu, C.; Zibordi, G. Spectral interdependence of remote-sensing reflectance and its implications on the design of ocean color satellite sensors. Appl. Opt. 2014, 53, 3301-3310. 
242. Lee, Z.; Carder, K.L. Effect of spectral band numbers on the retrieval of water column and bottom properties from ocean color data. Appl. Opt. 2002, 41, 2191-2201.

243. Lee, Z.P.; Rhea, W.J.; Arnone, R.; Goode, W. Absorption coefficients of marine waters: Expanding multiband information to hyperspectral data. IEEE Trans. Geosci. Remote Sens. 2005, 43, 118-124.

244. Defoin-Platel, M.; Chami, M. How ambiguous is the inverse problem of ocean color in coastal waters? J. Geophys. Res. Oceans (1978-2012) 2007, 112, C03004.

245. IOCCG. Remote Sensing of Inherent Optical Properties: Fundamentals, Tests of Algorithms, and Applications (Reports of the International Ocean-Colour Coordinating Group, No. 5); Technical Report; IOCCG Project Office: Dartmouth, Canada, 2006.

246. Brando, V.E.; Dekker, A.G.; Park, Y.J.; Schroeder, T. Adaptive semianalytical inversion of ocean color radiometry in optically complex waters. Appl. Opt. 2012, 51, 2808-2833.

247. Hoge, F.E.; Lyon, P.E. Spectral parameters of inherent optical property models: Method for satellite retrieval by matrix inversion of an oceanic radiance model. Appl. Opt. 1999, 38, 1657-1662.

248. Gordon, H.R.; Lewis, M.R.; McLean, S.D.; Twardowski, M.S.; Freeman, S.A.; Voss, K.J.; Boynton, G.C. Spectra of particulate backscattering in natural waters. Opt. Express 2009, 17, 16192-16208.

249. Gordon, H.R.; Morel, A.Y. Remote assessment of ocean color for interpretation of satellite visible imagery: A review. AGU 1983, 4, 1-114.

250. Hu, C.; Lee, Z.; Franz, B.A. Chlorophyll a algorithms for oligotrophic oceans: A novel approach based on three-band reflectance difference. J. Geophys. Res. Oceans (1984-2012) 2012, 117, C01011.

251. Huang, C.; Zou, J.; Li, Y.; Yang, H.; Shi, K.; Li, J.; Wang, Y.; Chena, X.; Zheng, F. Assessment of NIR-red algorithms for observation of chlorophyll-a in highly turbid inland waters in China. ISPRS J. Photogramm. Remote Sens. 2014, 93, 29-39.

252. Torrecilla, E.; Stramski, D.; Reynolds, R.A.; Millán-Núñez, E.; Piera, J. Cluster analysis of hyperspectral optical data for discriminating phytoplankton pigment assemblages in the open ocean. Remote Sens. Environ. 2011, 115, 2578-2593.

253. Hansell, R.A.; Tsay, S.C.; Pantina, P.; Lewis, J.R.; Ji, Q.; Herman, J.R. Spectral derivative analysis of solar spectroradiometric measurements: Theoretical basis. J. Geophys. Res. Atmos. 2014, 119, 8908-8924.

254. Philpot, W.D. The derivative ratio algorithm: Avoiding atmospheric effects in remote sensing. IEEE Trans. Geosci. Remote Sens. 1991, 29, 350-357.

255. Holden, H.; LeDrew, E. Spectral discrimination of healthy and non-healthy corals based on cluster analysis, principal components analysis, and derivative spectroscopy. Remote Sens. Environ. 1998, 65, 217-224.

256. Louchard, E.; Reid, R.; Stephens, C.; Davis, C.; Leathers, R.; Downes, T.; Maffione, R. Derivative analysis of absorption features in hyperspectral remote sensing data of carbonate sediments. Opt. Express 2002, $10,1573-1584$.

257. Lubac, B.; Loisel, H.; Guiselin, N.; Astoreca, R.; Artigas, L.F.; Mériaux, X. Hyperspectral and multispectral ocean color inversions to detect Phaeocystis globosa blooms in coastal waters. J. Geophys. Res. Oceans (1978-2012) 2008, 113, C06026.

258. Hunter, P.D.; Tyler, A.N.; Présing, M.; Kovács, A.W.; Preston, T. Spectral discrimination of phytoplankton colour groups: The effect of suspended particulate matter and sensor spectral resolution. Remote Sens. Environ. 2008, 112, 1527-1544.

259. Ali, K.A. Prediction of Water Quality Parameters from VIS-NIR Radiometry: Using Lake Erie as a Natural Laboratory for Analysis of Case 2 Waters. PhD Thesis, Kent State University, Kent, OH, USA, 2011.

260. Tufillaro, N.B.; Davis, C.O. Derivative spectroscopy with HICO. In Proceedings of the Optical Remote Sensing of the Environment, Monterey, CA, USA, 24-28 June 2012.

(C) 2015 by the authors; licensee MDPI, Basel, Switzerland. This article is an open access article distributed under the terms and conditions of the Creative Commons by Attribution (CC-BY) license (http:/ / creativecommons.org/licenses/by/4.0/). 